\title{
Genome-centric resolution of novel microbial lineages in an excavated Centrosaurus dinosaur fossil bone from the Late Cretaceous of North America
}

\author{
Renxing Liang ${ }^{1 *}$, Maggie C. Y. Lau ${ }^{1,2}$, Evan T. Saitta ${ }^{3}$, Zachary K. Garvin ${ }^{1}$ and Tullis C. Onstott ${ }^{1}$
}

\begin{abstract}
Background: Exceptional preservation of endogenous organics such as collagens and blood vessels has been frequently reported in Mesozoic dinosaur fossils. The persistence of these soft tissues in Mesozoic fossil bones has been challenged because of the susceptibility of proteins to degradation and because bone porosity allows microorganisms to colonize the inner microenvironments through geological time. Although protein lability has been studied extensively, the genomic diversity of microbiomes in dinosaur fossil bones and their potential roles in bone taphonomy remain underexplored. Genome-resolved metagenomics was performed, therefore, on the microbiomes recovered from a Late Cretaceous Centrosaurus bone and its encompassing mudstone in order to provide insight into the genomic potential for microbial alteration of fossil bone.

Results: Co-assembly and binning of metagenomic reads resulted in a total of 46 high-quality metagenomeassembled genomes (MAGs) affiliated to six bacterial phyla (Actinobacteria, Proteobacteria, Nitrospira, Acidobacteria, Gemmatimonadetes and Ch/oroflexi) and 1 archaeal phylum (Thaumarchaeota). The majority of the MAGs represented uncultivated, novel microbial lineages from class to species levels based on phylogenetics, phylogenomics and average amino acid identity. Several MAGs from the classes Nitriliruptoria, Deltaproteobacteria and Betaproteobacteria were highly enriched in the bone relative to the adjacent mudstone. Annotation of the MAGs revealed that the distinct putative metabolic functions of different taxonomic groups were linked to carbon, nitrogen, sulfur and iron metabolism. Metaproteomics revealed gene expression from many of the MAGs, but no endogenous collagen peptides were identified in the bone that could have been derived from the dinosaur. Estimated in situ replication rates among the bacterial MAGs suggested that most of the microbial populations in the bone might have been actively growing but at a slow rate.

(Continued on next page)
\end{abstract}

\footnotetext{
* Correspondence: rliang@princeton.edu

'Department of Geosciences, Princeton University, B88, Guyot Hall, Princeton University, Princeton, NJ 08544, USA

Full list of author information is available at the end of the article
}

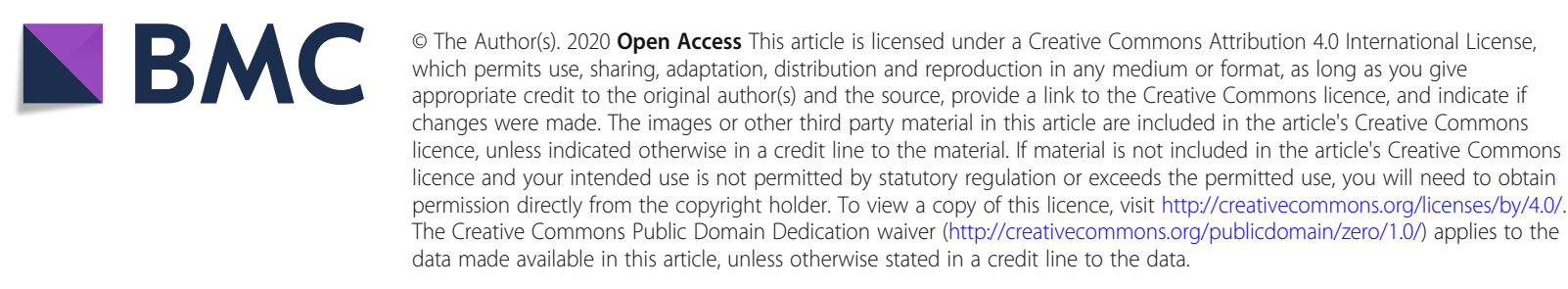




\begin{abstract}
(Continued from previous page)
Conclusions: Our results indicate that excavated dinosaur bones are habitats for microorganisms including novel microbial lineages. The distinctive microhabitats and geochemistry of fossil bone interiors compared to that of the external sediment enrich a microbial biomass comprised of various novel taxa that harbor multiple gene sets related to interconnected biogeochemical processes. Therefore, the presence of these microbiomes in Mesozoic dinosaur fossils urges extra caution to be taken in the science of paleontology when hunting for endogenous biomolecules preserved from deep time.
\end{abstract}

Keywords: Centrosaurus fossil bone, Diagenesis, Rare Actinobacteria, Halotolerant bacteria, Late Cretaceous, Uncultured microbial lineages

\section{Background}

Persistence of endogenous organic remains such as DNA and proteins in Mesozoic dinosaurs has long been deemed unlikely due to their lability and gradual breakdown through deep time and diagenesis [1-3]. However, a series of groundbreaking studies has proposed through structural observations, immunohistochemistry, proteomics and in situ microspectroscopic methods [4-11] that endogenous organics such as collagens, blood vessels, erythrocytes and osteocytes appear to be organically preserved in various dinosaur fossils with relatively limited alteration. The reports of collagen peptides from Mesozoic dinosaur fossils are often viewed as particularly exciting in paleontology as they, if genuine, could dramatically enhance our understanding of the evolutionary biology of extinct organisms through deep time [5]. Despite the increasing number of reports about the preservation of endogenous biocomponents in dinosaur fossils over the last decade, their existence remains controversial due to concerns about exogenous contamination from microbial biofilms [12] and other sources associated with analytical procedures [13-15], and to the difficulty in reasonably explaining the mechanisms for their exceptional preservation [5].

Regardless of the authenticity of the preserved endogenous organics in dinosaur fossils, the alternative hypothesis pertaining to microbial biofilms is particularly intriguing from the viewpoint of microbial ecology. Microbial communities from the past and present are well-known to play different roles in biodegradation and biomineralization at various stages throughout the taphonomic history of fossils [16-19]. On the one hand, endogenous organics including soft tissues inside the bone could be rapidly decomposed by intensive metabolic activity of microorganisms after the death of vertebrates [20]. On the other hand, other taphonomic studies have shown that, in some circumstances, microbes might facilitate exceptional preservation of certain soft tissues during post-mortem decay through authigenic mineralization via replacement with phosphates or pyrite [18, 21-23]. The retention of primary soft-tissues within vertebrate bone has been suggested to be enhanced by porosity and permeability reduction from mineral precipitation by microbial biofilms within the bone that are involved in the decomposition of organic matter at early taphonomic stages [23]. It should be noted that the decreasing permeability would not change any inherent thermodynamic instability of these soft tissues, and microscopic cracking can occur in bone apatite as a result of collagen hydrolytic fragmentation, gelatinization, and swelling through hydration [24, 25]. Extreme examples of likely microbially mediated mineralization trapping fossil organics like melanin or steroids, albeit diagenetically altered, are carbonate concretions from the Mazon Creek Formation [26, 27].

The porosity and permeability structure of fossil bone determine the microbial and nutrient exchanges between the bone and the host strata throughout geological time [28]. Therefore, the dynamics of microbial colonization inside the fossil bone would be dependent upon the continuous interaction with the changing hydrogeological environment from post-mortem to recent exposure. Several studies have documented the microbial diversity and activity in relatively recent fossil remains from diverse environments [29-32]. The microbial community profile revealed that most of the DNA obtained from $200 \mathrm{yr}$ to 20 kyr old bones originated from microorganisms that had recently colonized them from the host sediment [29, 30]. Although soft tissues preserved in Mesozoic dinosaur bone have been alternatively interpreted as modern microbial biofilms [12], the microbiome associated with such fossils from deep time remains largely ignored during paleontological and taphonomic studies. In a previous study [28], we analysed freshly-excavated, asepticallyacquired, Late Cretaceous Centrosaurus bones and sediment matrix from the Dinosaur Park Formation with a combination of microbiological and chemical techniques. The $16 \mathrm{~S}$ rRNA gene amplicon survey revealed a diverse microbial community residing within the dinosaur bone. Moreover, several novel microbial lineages were found to be more abundant in the bone than in the surrounding sediment [28].

Due to the limited length of the targeted V4 region of the 16S rRNA gene used in amplicon sequencing [28], the taxonomic status of the dominant novel microbial 
lineages inside the bone could not be well resolved [28]. Moreover, the molecular survey based on a single biomarker gene precluded us from gaining insight into the potential metabolic functions and their possible ecological roles in biogeochemical cycling and potential taphonomic alteration in fossil bones. To circumvent these limitations, we employed genome-resolved metagenomics with deep sequencing to directly infer the metabolic potential and taxonomic novelty of the predominant microbial populations residing within the Centrosaurus bone. By using a co-assembly and consolidated binning strategy [33], we were able to reconstruct 46 metagenome-assembled genomes (MAGs) identified as uncultivated, novel taxonomic lineages varying from class to species level. The enrichment of MAGs from Nitriliruptoria, Deltaproteobacteria and Betaproteobacteria inside the bone suggested that nutrients inside the bone microenvironments facilitated the propagation of these microbial populations during its recent taphonomic history.

\section{Methods}

\section{Sampling site and fossil bone excavation}

A bonebed (BB180) containing Centrosaurus apertus (Ornithischia; Ceratopsidae) in the Late Campanian Dinosaur Park Formation was sampled in 2016 in Dinosaur Provincial Park, Alberta, Canada $(50.75 \mathrm{~N} ; 111.4 \mathrm{~W})$. The Dinosaur Park Formation contains alluvial, estuarine, and paralic sedimentary facies deposited during the transgression of the Western Interior Seaway (Bearpaw Sea) in southern Alberta [34]. According to the chronostratigraphic record, the Dinosaur Park Formation interfingers with brackish and marine shales of the overlying Bearpaw Formation [34] and represents one of the units comprising the Judith River Aquifer [35]. The formation of the bone beds appears related to coastal-plain flooding, leading to rapid burial [34]. The Cretaceous strata were subsequently overlain by 1600 to $3800 \mathrm{~m}$ of early Tertiary sediments which were later removed by erosion after the Early Eocene $[36,37]$. During this interval the strata attained maximum burial temperatures of $90-120^{\circ} \mathrm{C}$, and $\delta^{18} \mathrm{O}$ analyses of diagenetic minerals suggested that the formation water was always dominated by fresh meteoric water, especially during post-Early Eocene erosion [36]. Glacial ice sheets up to 2 $\mathrm{km}$ thick covered the strata during the Pleistocene [37] during which the strata were recharged with fresh, $\mathrm{Na}-\mathrm{HCO}_{3}-$ $\mathrm{Cl}$ water like that of the Milk River aquifer immediately to the south $[37,38]$. Nonetheless the hydrology of these strata is complicated leading to enormous salinity gradients, and the sampling site is located $<10 \mathrm{~km}$ from a well where a $\mathrm{Na}-\mathrm{Cl}$ formation water salinity exceeds $15,000 \mathrm{ppm}$ [37] and this salinity likely originates from the bounding marine shales [39].
The detailed aseptic sampling and transport procedures and the permit documents for collecting dinosaur bones were previously described [28]. Briefly, the Centrosaurus bones were first partially exposed at one end from a vadose zone outcrop after removing the sandstone and mudstone overburden from the bone-bearing horizon. In order to minimize contamination, a small, partial Centrosaurus rib sample, representing the unexposed end, and the surrounding adjacent mudstone were collected together as a whole using sterilized equipment. The collected bone samples were immediately stored on ice in a cooler before transporting to the camp freezer [28]. All samples were shipped to Princeton University on blue ice packs and stored at $-80^{\circ} \mathrm{C}$ prior to DNA extraction and other analyses.

\section{Bone pretreatment and geochemical characterization}

The mudstone encapsulated bone was processed inside a UV sterilized laminar flow hood. The fossil bone fragments and adjacent mudstone were carefully separated and bone surface was scraped off (hereafter referred to as scrapings) with a flame-sterilized autoclaved razor. The cleaned bone with outer surface removed, along with the scrapings and the surrounding mudstone matrix were powdered separately with sterilized mortars and pestles. To determine the water-extractable anions, $0.1 \mathrm{~g}$ of each powder fraction was thoroughly mixed with $1 \mathrm{~mL}$ Milli-Q $\mathrm{H}_{2} \mathrm{O}$ and incubated overnight before measurement. The slurry was centrifuged at $14,000 \times \mathrm{g}$ for $5 \mathrm{~min}$ and the supernatant was then filtered with $0.22 \mu \mathrm{m}$ filter membrane for ion chromatography analyses. All samples (in triplicate) were analyzed on a Dionex chromatography system equipped with an IC25 Ion Chromatograph, AS40 autosampler, a LC25 chromatography oven and an EG40 eluent generator. Anions were separated using a Dionex IonPac AS15 $(3 \times 150 \mathrm{~mm})$ analytical column connected to a Dionex IonPac AG15 $(3 \times 50 \mathrm{~mm})$ guard column. The oven was maintained at $30^{\circ} \mathrm{C}$ and the flow rate was set at $0.35 \mathrm{~mL} / \mathrm{min}$. The $\mathrm{KOH}$ gradient generated by the EG40 eluent generator was as follows: 0-10 min, $5 \mathrm{mM} ; 10-16 \mathrm{~min}$, gradient from 5 to $40 \mathrm{mM} ; 16-30$ $\mathrm{min}$, isocratic at $40 \mathrm{mM} ; 30-33,40 \mathrm{mM}$ to $5 \mathrm{mM}$; and a final isocratic run $(33-40 \mathrm{~min})$ at $5 \mathrm{mM}$.

\section{DNA extraction and metagenomic sequencing}

The DNA used in this study was the same material recovered from the bone, adjacent mudstone and scrapings as described in our previously publication [28]. Briefly, DNA was extracted from powdered bone $(5 \mathrm{~g})$, a slurry of EDTA demineralized bone $(5 \mathrm{~g})$, and mudstone $(10 \mathrm{~g})$ using DNeasy PowerMax Soil Kit (QIAGEN, Germany) according to the manufacturer's instruction. The EDTA demineralized bone was incorporated for 
DNA extraction because pre-treatment with EDTA has been frequently used to remove the mineral phase to recover collagen peptides from dinosaur bones in previous studies $[6-8,40]$. A negative control with bone- and mudstone-free reagents were incorporated to monitor contaminant DNA that could be introduced during DNA extraction from the reagents and laboratory environments. The DNA yield in the blank control was found to be below detection $(<0.01 \mathrm{ng} / \mu \mathrm{L})$ [28] and thus was not included for subsequent metagenomic sequencing.. The library preparation for the resultant DNA from each sample was performed using Nextera DNA Library Prep kit (Illumina, San Diego, CA, USA). The library from each sample with unique barcode were pooled and then sequenced on an Illumina Hiseq 2500 (150-bp, paired-end) at the Genomics Core Facility, Princeton University. Three metagenomes from the bone powder (1B5g), EDTA-treated bone powder (1BEDTA) and adjacent mudstone $(1 \mathrm{M} 10 \mathrm{~g})$ were generated with a total of $\sim 120$ million paired-end reads of $2 \times 150 \mathrm{bp}$.

\section{Contigs assembly and reconstruction of MAGs}

The raw sequences were quality-filtered using the Trim Galore pipeline in the Galaxy server at Princeton University (http://galaxy.princeton.edu) as described previously [41]. The clean reads from the three metagenomes were co-assembled with MEGAHIT v1.1.4 [42] using paired-end mode with the settings of $k$-min $=27, k$ $\max =137, k$-step $=10$. The co-assembled contigs $(>1.5 \mathrm{~kb})$ were binned with three different tools, namely MetaBAT v 2.12.1, [43], MaxBin v2.0 [44] and CONCOCT v1.1.0 [45] using the default settings in the "Binning module" implemented in MetaWRAP v0.8 [33]. The MAGs generated with the above three different algorithms were consolidated with the "Bin_refinement module" in MetaWRAP v0.8 [33] using a minimum cutoff value of $80 \%$ for completeness and a maximum cutoff value of $10 \%$ for contamination as assessed by CheckM v1.0.11 [46]. The consolidated MAGs were further reassembled with the "Reassemble_bins module" in MetaWRAP v0.8 [33]. Briefly, all metagenomics reads were mapped back to each MAG with "strict" (exact match) and "permissive" (allowing 3 mismatches) options. The mapped reads from each MAG were then reassembled using SPAdes v3.13.0 [47] and a set of k-mer sizes (21, 33, $55,77)$ in MetaWRAP v0.8 [33]. The quality of the reassembled MAGs were assessed with CheckM v1.0.11 [46] and those MAGs with a minimum completeness of $90 \%$ and a maximum contamination of $10 \%$ were retained for downstream analyses.

\section{Metabolic annotation and phylogenetic analyses}

The functional genes (protein coding sequences, CDS) from all MAGs were predicted and annotated using
Prokka v1.13 [48] and DFAST tools [49] against TIGRFAM and COG databases. The identified functional genes encoding enzymes of interest, such as microbial collagenase, alkane 1-monooxygenase and naphthalene 1,2-dioxygenase were confirmed by blastp against NCBI $\mathrm{nr}$ database when needed. The metabolic pathways for major nutrients metabolism such as carbon and nitrogen were predicted using the automated annotation server RAST (Rapid Annotation using Subsystem Technology) [50] and the KEGG BlastKOALA tool [51] with the default settings.

The 16S rRNA gene in the MAGs was retrieved using the commands (anvi-script-FASTA-to-contigs-db GENOME.fa and anvi-get-sequences-for-hmm-hits -c GENOME.db --hmm-source Ribosomal_RNAs) implemented in Anvi'o 5.2 [52] and RNAmmer 1.2 [53]. The closely related 16S rRNA gene sequences (top 3 hits) from both cultured and uncultured microorganisms were retrieved from the NCBI GenBank database. All 16S rRNA gene sequences were aligned with MUSCLE v3.8.31 [54] and the phylogenetic tree was constructed using the Maximum Likelihood method based on the Tamura-Nei model using MEGA v7.0.20 [55]. Phylogeny of the MAGs from this study and their close relatives (MAGs or genomes of cultivated organisms from NCBI database, accessed in April, 2019) was also assessed based on the same concatenated 16 single-copy ribosomal proteins that had been used to construct the tree of life [56]. The sequences of the ribosomal proteins were extracted from all MAGs and further concatenated for alignment with MUSCLE v3.8.31 in Anvi'o 5.2 [52]. The alignment of the concatenated amino acid sequences was trimmed using trimAl v.1.2 [57] and then the phylogenetic tree was constructed with RAxML v. 8.1.17 [58] using the PROTGAMMAILGF model for amino acid sequence evolution and 1000 bootstraps. The newick tree was viewed and refined using the online iTOL software [59].

\section{Other genome-centric analyses}

The taxonomic classification of all MAGs was also performed using Genome Taxonomy Database Toolkit (GTDB-Tk v 0.3.0) [60] to support the novelty of these microbial lineages. The phylogenetic placement in GTDB-Tk was based on multiple sequence alignment of 120 bacterial and 122 archaeal marker genes from MAGs and the most comprehensive genomes collection in the database (release R04-RS89, June 19th, 2019). Due to the taxonomic novelty of most MAGs, average amino acid identity (AAI) between particular MAGs and other publicly available genomic relatives was calculated using the command (aai-matrix.bash) implemented in the Enveomics toolbox [61]. The relative abundance of all MAGs across the bone, EDTA-treated bone and adjacent 
mudstone was calculated using the "Quant_bin" module in MetaWRAP v0.8 [33]. According to the taxonomic assignment of each MAG, the microbial community was also constructed by grouping all MAGs into their affiliated taxa at various taxonomic levels. In order to further characterize gene functions in the dominant MAGs in the bone, the gene clusters that are different from genomes from other environments were identified and visualized using the pangenomics workflow in Anvi'o v5.2 [52] with the following parameters (anvi-pan-genome -g Euzebya-GENOMES.db । --project-name "Euzebya_Pan_new" \--output-dir Euzebya $\backslash$--num-threads $12 \backslash$--minbit $0.5 \backslash$--mcl-inflation 2) Lastly, the Growth Rate Index (GRiD) was calculated from all bacterial MAGs to infer in situ growth rates of microbial populations in the bone and adjacent mudstone based on the ratio of coverage at the peak (origin of replication, ori) and trough (terminus, ter) regions as determined by mapping the metagenomic reads to each MAG [62]. The validity of GRiD values was further tested using the coverage information of chromosome initiator replication gene $(d n a A)$ and deletion-induced filamentation (dif) sequences across the genome [62]. The GRiD values from the MAGs are considered valid for downstream analyses only if the dnaA/ori and ter/dif coverage ratios are above 0.8 and the species heterogeneity is low $(<0.3)$.

\section{Re-analyses of 16S rRNA gene amplicon data}

Although a preliminary analysis of $16 \mathrm{~S}$ rRNA gene amplicon data has been reported [28], a more in-depth examination of the same dataset was performed to support the genome-centric analyses in this work. The relative abundance of predominant microbial lineages in the dinosaur bone and adjacent mudstone replicates were calculated for pair-wise comparison at various taxonomic levels depending on the resolution of $16 \mathrm{~S}$ rRNA gene amplicon approach. P-values were derived from Student's t-test to determine whether there were any significant differences in the major taxonomic groups between the bone and adjacent mudstone. The OTU Table (11,467 OTUs across 8 samples) previously generated [28] and all available geochemical parameters were used to perform Canonical Correspondence Analysis (CCA) using the vegan and phyloseq packages [63] in R software v3.5.1. Additionally, the relative abundance of the dominant taxa at the class level was incorporated in the CCA plot to examine their correlation with the geochemical data. The distance matrix for the ordination was based on Bray-Curtis distances and the explanatory variables were chosen by stepwise model selection with permutation tests.

\section{Metaproteomic analyses}

Due to the inherent challenges associated with protein extraction from fossil bones with low biomass, four different approaches were used to extract proteins from the fossil bone and adjacent mudstone. In the first protocol fractions containing proteins (precipitates collected from step 7 and 10 of the DNA extraction procedures described above) from the mudstone and EDTA-treated bone were subject to protein purification using a standard methanol/acetone protocol as described previously [64]. The second protocol was adapted from an earlier study [40] that reported the successful identification of collagen peptides from fossil specimens of Brachylophosaurus Canadensis. Briefly, direct protein extraction was attempted by incubating the bone and mudstone powder $(1 \mathrm{~g}$ each) with $6 \mathrm{M}$ guanidine- $\mathrm{HCl}$ at $65{ }^{\circ} \mathrm{C}$ overnight to dissolve any potential endogenous collagen peptides; In the third protocol the proteins were extracted using a previously described method optimized for soil metaproteomics [65]. Bone and mudstone powder $(5 \mathrm{~g}$ of each) were thoroughly mixed with $10 \mathrm{~mL}$ alkaline SDS (sodium dodecyl sulphate) buffer and then incubated in water bath $\left(100^{\circ} \mathrm{C}\right)$ for 10 mins. The protein was recovered by trichloroacetic acid precipitation and further cleaned following acetone wash as previously described [65]. The fourth protocol utilized a commercial kit (NoviPure Soil Protein Extraction Kit, QIAGEN, Germany) to extract proteins from the bone $(3 \mathrm{~g})$ and mudstone powder $(5 \mathrm{~g})$ following the manufacture's procedures.

The protein pellets from each extraction method were dissolved in $6 \mathrm{M}$ guanidine- $\mathrm{HCl}$ and sonicated 5 times for $30 \mathrm{~s}$ with $1 \mathrm{~min}$ rest on ice in between each cycle. Tris(2- carboxyethyl)phosphine (TCEP) was added to $5 \mathrm{mM}$ final concentration and incubated at $60^{\circ} \mathrm{C}$ for $10 \mathrm{~min}$. Chloroacetamide was added $(15 \mathrm{mM})$ and then incubated in the dark at room temperature for further $30 \mathrm{~min}$. Samples were diluted 1:10 with digestion buffer (10\% Acetonitrile, $25 \mathrm{mM}$ Trish pH 8.5) and $2 \mu \mathrm{g}$ of Trypsin Gold (Promega) was added to each sample and incubated end-over-end at $37^{\circ} \mathrm{C}$ for $16 \mathrm{~h}$. Samples were acidified by adding trifluoroacetic acid $(0.2 \%$ final concentration) and were further desalted using Stage Tips [66]. Samples were dried completely in a SpeedVac and resuspended with $20 \mu \mathrm{L}$ of $0.1 \%$ formic acid (pH3). A $5 \mu \mathrm{L}$ aliquot of the sample was injected per run using an Easy-nLC 1200 UPLC system. Samples were loaded directly onto a $45 \mathrm{~cm}$ long $75 \mu \mathrm{m}$ inner diameter nano capillary column packed with $1.9 \mu \mathrm{m}$ C18-AQ (Dr. Maisch, Germany) mated to metal emitter in-line with an Orbitrap Fusion Lumos (Thermo Scientific, USA). The mass spectrometer was operated in data dependent mode with the 120,000 resolution MS1 scan (AGC 4e5, Max IT $50 \mathrm{~ms}, 400-1500 \mathrm{~m} / \mathrm{z}$ ) in the Orbitrap followed by up to $20 \mathrm{MS} / \mathrm{MS}$ scans with CID fragmentation in the ion trap. Dynamic exclusion list was invoked to exclude previously sequenced 
peptides for 60s if sequenced within the last $30 \mathrm{~s}$ and maximum cycle time of $3 \mathrm{~s}$ was used. Ion-trap was operated in Rapid mode with AGC target 2e3, maximum IT of $300 \mathrm{~ms}$ and minimum of 5000 ions.

Protein identification from all metaproteomes was performed against various databases with the open-source software MaxQuant (v. 1.6.0.1) [67]. To identify collagen peptides potentially preserved in the fossil bone, a database was built using all protein sequences from the Uniprot Vertebrates database and collagen peptides reported from Mesozoic dinosaur fossils $[8,10]$. The proteome (all CDSs) from all MAGs were predicted by Prodigal [68] and then merged to create another database for identifying expressed proteins from the microbial populations residing in the fossil bone. The cleavage enzyme Trypsin/P was selected and two missed cleavages were allowed. Contaminant sequences such as human keratins, chicken collagens, and bovine serum albumin were automatically included during the search with MaxQuant v1.6.0.1 [67]. The maximum falsediscovery rate was set to 0.05 for both the peptidespectrum matches (PSMs) and proteins using the target-decoy strategy. The validity of identified proteins was based on the criterion of at least one unique peptide per protein.

\section{Results and discussion}

\section{Geochemical characteristics and correlation to microbial} community

The $\mathrm{pH}$ of the water extract from the bone was 5 whereas that of the adjacent mudstone was 6.5. The slightly acidic microenvironments inside the Centrosaurus bone might facilitate dissolution of hydroxyapatite and contribute to the observed higher concentration of water soluble $\mathrm{PO}_{4}{ }^{3-}$ in the bone relative to the mudstone (Additional file 2: Table S1). The concentration of $\mathrm{SO}_{4}{ }^{2-}$ and $\mathrm{NO}_{3}{ }^{-}$was much higher than other anions $\left(\mathrm{F}^{-}, \mathrm{Cl}^{-}, \mathrm{PO}_{4}{ }^{3-}, \mathrm{NO}_{2}{ }^{-}\right)$in both the bone and the mudstone (Additional file 2: Table S1). Surprisingly, the $\mathrm{SO}_{4}{ }^{2-}$ and $\mathrm{NO}_{3}{ }^{-}$concentrations in the bone were 10 times $(4910 \mu \mathrm{g} / \mathrm{g})$ and two times $(1210 \mu \mathrm{g} / \mathrm{g})$ higher, respectively, than those in the adjacent mudstone suggesting a more oxidizing microenvironment. Formate, acetate, lactate and proprionate were below detection limits $(1.3 \mu \mathrm{g} / \mathrm{g})$ in both the bone and the mudstone. The CCA analysis revealed that $\mathrm{pH}, \mathrm{SO}_{4}{ }^{2-}$ and $\mathrm{NO}_{3}{ }^{-}$were more important in influencing the microbial community in the bone relative to other geochemical parameters (Additional file 1: Fig. S1). Our previous 16S rRNA gene amplicon data revealed that the classes Nitriliruptoria, Acidimicrobiia, Betaproteobacteria and Deltaproteobacteria were more abundant in the Centrosaurus bone relative to the mudstone [28]. The statistically significant difference between bone and adjacent mudstone was supported by performing pair-wise comparison of the dominant groups (Additional file 2: Fig. S2). The CCA analysis suggests that these dominant classes in the bone were positively correlated with $\mathrm{SO}_{4}{ }^{2-}$ and $\mathrm{NO}_{3}{ }^{-}$ (Additional file 1: Fig. S1). In contrast, the most abundant Actinobacteria in the mudstone was negatively correlated with $\mathrm{SO}_{4}{ }^{2-}$ and $\mathrm{NO}_{3}{ }^{-}$(Additional file 1: Fig. S1), suggesting that these common soil Actinobacteria lineages prefer to reside in less oxidized environments.

\section{Reconstruction of MAGs representing phylogenetically novel lineages}

A total of 180,537 contigs $(\geq 1 \mathrm{~kb})$ were co-assembled from three metagenomes (1B5g, 1BEDTA and 1M10g) with a combined input of $\sim 120$ million quality-filtered reads (paired-end, 150-bp). By integrating 3 different algorithms and a consolidation strategy [33], we were able to recover 59 MAGs ( $>80 \%$ complete and $<10 \%$ contamination) from the co-assembled contigs. Further re-assembly resulted in 46 MAGs ( $90 \%$ complete) that were selected for downstream analyses (Additional file 3: Table S2). According to the standards proposed by Bowers et al. [69], all MAGs qualified as high-quality draft genomes ( $>90 \%$ complete and $<5 \%$ contamination) except that the contamination level of three MAGs (Dino_bin7, 6.15\%; Dino_bin26, 6.36\%; and Dino_bin50, $5.13 \%$ ) was slightly above $5 \%$ (Additional file 3 : Table S2).

According to phylogenomic analyses (Fig. 1) and genome-based taxonomy (GTDB-Tk) (Additional file 4: Table S3), the taxonomic annotation revealed that these 46 high-quality MAGs represent 6 bacterial phyla (Actinobacteria, Proteobacteria, Nitrospira, Acidobacteria, Gemmatimonadetes and Chloroflexi) and 1 archaeal phylum (Thaumarchaeota). No MAGs or contigs belonging to Eukaryotes, such as Fungi, were detected. The clustering of $1 \mathrm{~B} 5 \mathrm{~g}$ and $1 \mathrm{BEDTA}$ relative to $1 \mathrm{M} 10 \mathrm{~g}$ based upon the relative abundance of the MAGs further confirmed the distinct microbial community structure of the bone versus that of the mudstone [28] (Fig. 2). The MAGs associated with Delatproteobacteria (Dino_ bin29), Nitriliruptoria (Dino_bin24) and Betaproteobacteria (Dino_bin43) were more abundant (4-13 times) inside the bone than the mudstone, whereas many Actinobacteria MAGs (Dino_bin2, Dino_bin12 and Dino_bin14, Dino_bin25 and Dino_bin55) were more abundant in the mudstone than the bone (Fig. 2 and Additional file 5: Table S4). Overall, the MAGs of the bone microbial community represented the same dominant microbial lineages (Fig. 2 and Additional file 1: Fig. S2) as previously determined by $16 \mathrm{~S}$ rRNA gene amplicon sequencing with Nitriliruptoria (Dino_bin24) comprising $26-28 \%$ of the Centrosaurus bone microbiome [28]. 


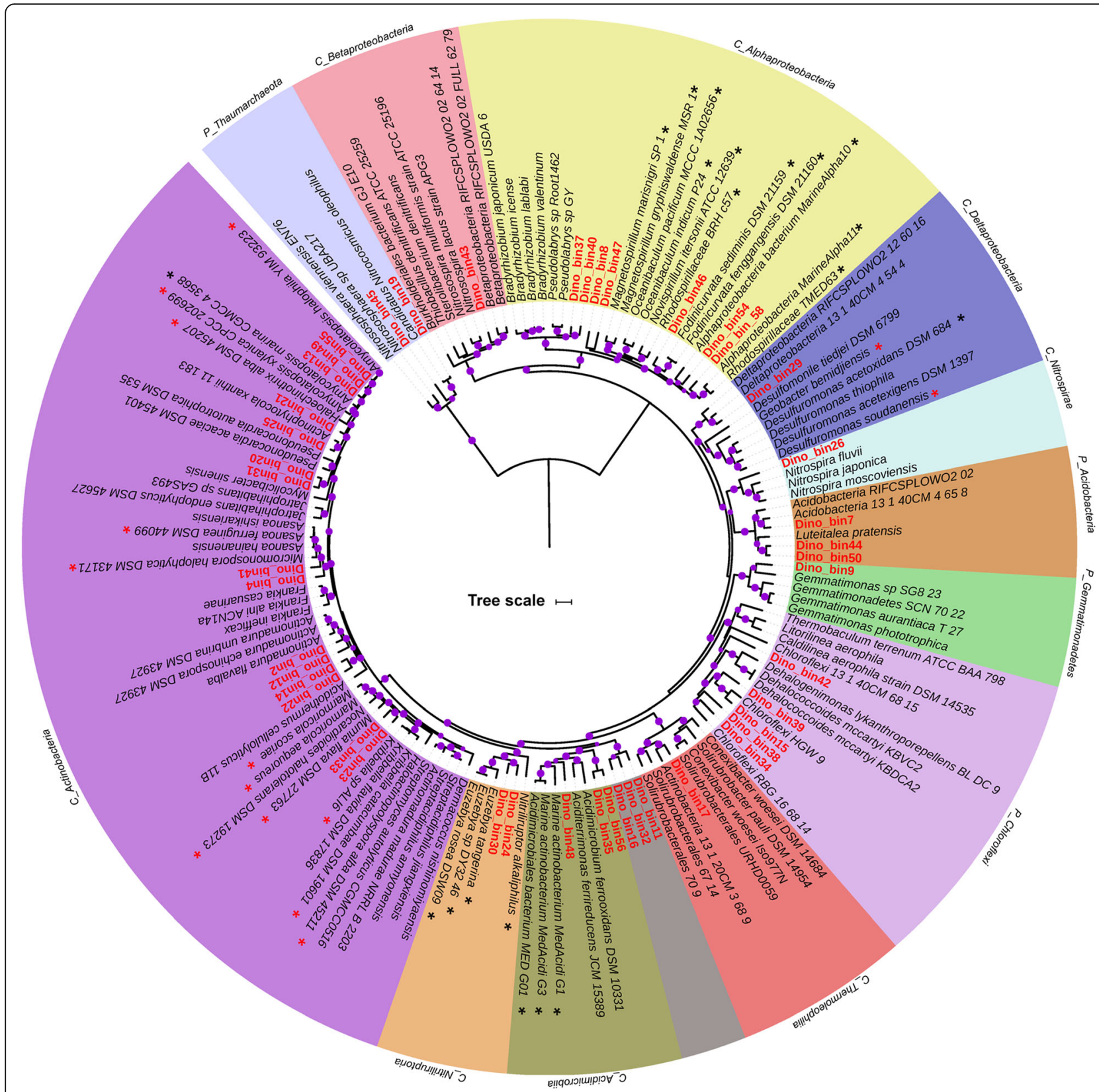

Fig. 1 Phylogenetic tree of MAGs and their close genomic representatives from diverse environments. The Maximum-likelihood phylogenomic tree was based on 16 concatenated ribosomal proteins. The black and red asterisks indicate those microorganisms originating from marine environments and hypersaline environments such as salt lakes and subsurface brines, respectively. The purple dots represent bootstrap values $>70 \%$ (bootstrap values were generated from 1000 replications) whereas the bootstrap value of those nodes without a dot was less than 70\%. Note: The taxa starting with " $\mathrm{P}$ " and " $\mathrm{C}$ " refer to their taxonomic level of phylum and class, respectively. The scale bar corresponds to 0.1 substitutions per amino acid position

The phylogenomic tree revealed that many of the MAGs were distantly related to the publicly available genomes as evidenced by their formation of separate clades (Fig. 1). Such observations underline the phylogenetic novelty of microbial populations from the Centrosaurus fossil bone. Notably, the Actinobacteria MAGs (Dino_ bin11, Dino_bin16 and Dino_bin32) are placed within a novel clade with no previously reported neighboring genomic relatives and thus might represent a novel class or order within the phylum Actinobacteria. Partial to nearly full-length $16 \mathrm{~S}$ rRNA genes were recovered from 15 of the MAGs (Additional file 6: Table S5) to construct a phylogenetic tree with their close relatives of uncultivated and cultivated organisms (Fig. 3). The 16S 


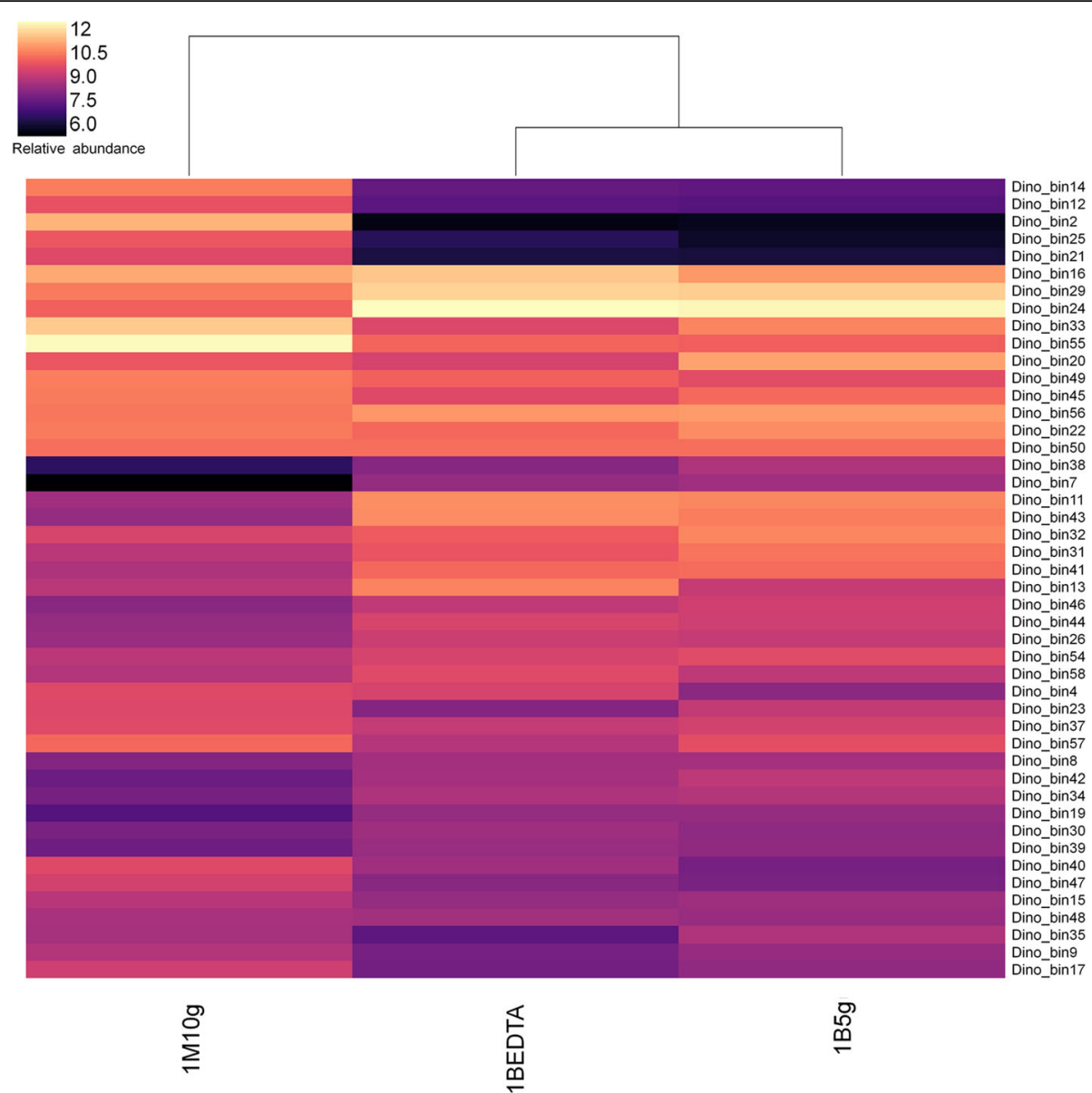

Fig. 2 Relative abundance of MAGs across the three metagenomes (1B5g, 1BEDTA and 1M10g). The abundance of each MAG was calculated from the reads mapped in the metagenome and normalized to the individual sample size as genome copies per million reads

rRNA genes from the 15 MAGs closely clustered with environmental sequences from uncultivated bacteria as separate clades (Fig. 3). All 15 MAGs except for the Nitrospira-like organism (Dino_bin26, 98\% identical to Nitrospira marina $\mathrm{Nb}-295)$ were tentatively identified as novel lineages at least at the species level based on the low homology (84-95\%) with known cultivated microbes (Additional file 6: Table S5). Among them, the MAGs affiliated with Deltaproteobacteria (Dino_bin29), Chloroflexi (Dino_bin34, Dino_bin38, and Dino_bin39) and Actinobacteria (Dino_bin11, Dino_bin16 and Dino bin32) might represent novel classes or orders in light of the low similarity $(84-87 \%)$ of their $16 \mathrm{~S}$ rRNA gene to that of known microbes (Additional file 6: Table S5). The taxonomic classifications assigned by the GTDB-Tk tool [60] confirmed that the abovementioned 7 MAGs can only be identified to class or order level from genomic comparison to the genome collection in the latest database (Additional file 4: Table S3). The taxonomic novelty of these MAGs was further supported by the extremely low AAI values (Additional file 1: Fig. S3-S7) based on the previously proposed thresholds for species (95\%) and genus (65\%) [70]. For the MAGs affiliated with Chloroflexi (Dino_bin42), Deltaproteobacteria (Dino_bin29) and Actinobacteria (Dino_bin11, Dino_ bin16 and Dino_bin32), the maximum AAI value was generally below $\sim 50 \%$ when compared with the closely related genomic representatives (Additional file 1: Fig. S5-S7). Therefore, the majority of the reconstructed MAGs belong to completely new microbial lineages at least at species level based on 16S rRNA phylogeny, phylogenomics, AAI profiling and genome-based taxonomy.

\section{Prevalence of halotolerant organisms in the Centrosaurus fossil bone}

Several of the dominant lineages including Euzebyales (Dino_bin24 and Dino_30), Acidimicrobiia (Dino_bin48) and most of the Alphaproteobacteria MAGs (Dino bin46, Dino_bin54 and Dino_bin58) were phylogenetically related to microorganisms originating from marine environments (Fig. 1). The two predominant Euzebyalesrelated MAGs (Dino_bin24 and 30) in the bone were 


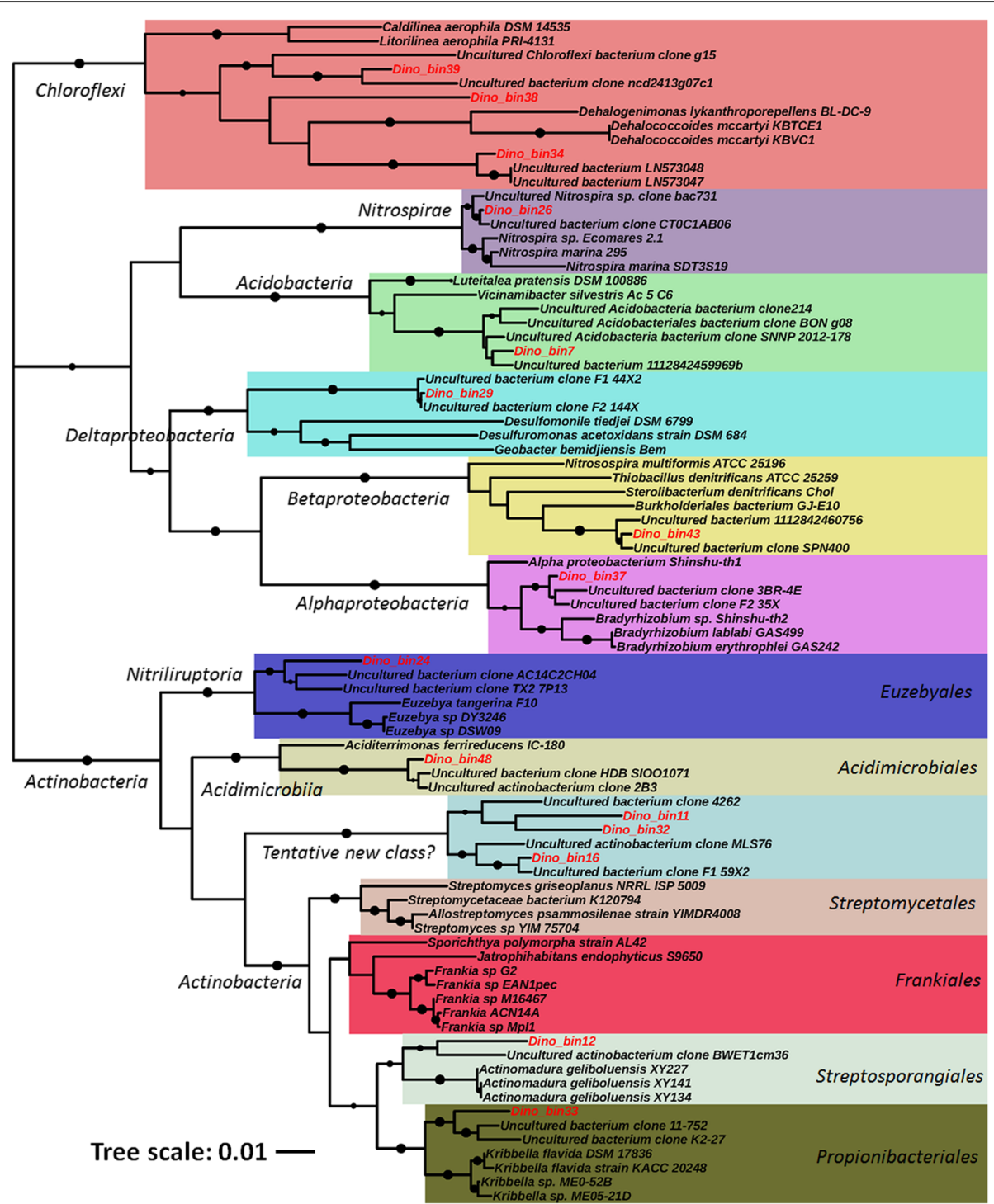

Fig. 3 Phylogenetic tree based on 165 rRNA genes from MAGs and close relatives of culture and uncultured organisms. The black dots represent bootstrap values $>70 \%$ (bootstrap values were generated from 1000 replications). The 16S rRNA genes from MAGs in this study were highlighted in bold and red. The scale bar corresponds to 0.01substitutions per nucleotide position

closely related to Actinobacteria (Euzebya spp.) isolated from various marine environments in Japan and China [71-73]. Pangenomics analysis of the Euzebya-related MAGs revealed that three gene clusters were present in the terrestrial MAGs from the Centrosaurus bone but absent from the marine counterparts (Additional file 1: Fig. S8). Additionally, the Acidimicrobiia-related MAG (Dino_bin48) and Alphaproteobacteria MAGs (Dino_ bin46, Dino_bin54 and Dino_bin58) were most phylogenetically related to draft genomes recovered from the Mediterranean deep chlorophyll maximum [74] and Tara Oceans metagenomic datasets $[75,76]$, respectively. Moreover, the Nitrospira-related MAG (Dino_bin_26) showed the highest similarity $(\sim 98 \%)$ to marine nitrite- oxidizers such as Nitrospira marina [77] and Nitrospira marina Ecomares 2.1 [78] based on 16S rRNA phylogeny (Fig. 3 and Table S4). Apart from microorganisms from marine environments, the Deltaproteobacteria MAG (Dino_bin29) and many Actionbacteria MAGs (Dino_bin23, Dino_bin33, Dino_bin4, Dino_bin41, Dino_bin13, Dino_bin49, Dino_bin55) were closely related to microorganisms found in other high salinity environments such as salt lakes, mangrove soil and subsurface brine (Fig. 1).

Many of the MAGs harbor genetic machinery for osmoregulation, uptake and synthesis of osmoprotective compounds in order to cope with potentially high osmotic stress (Fig. 4). The genes encoding osmolarity 


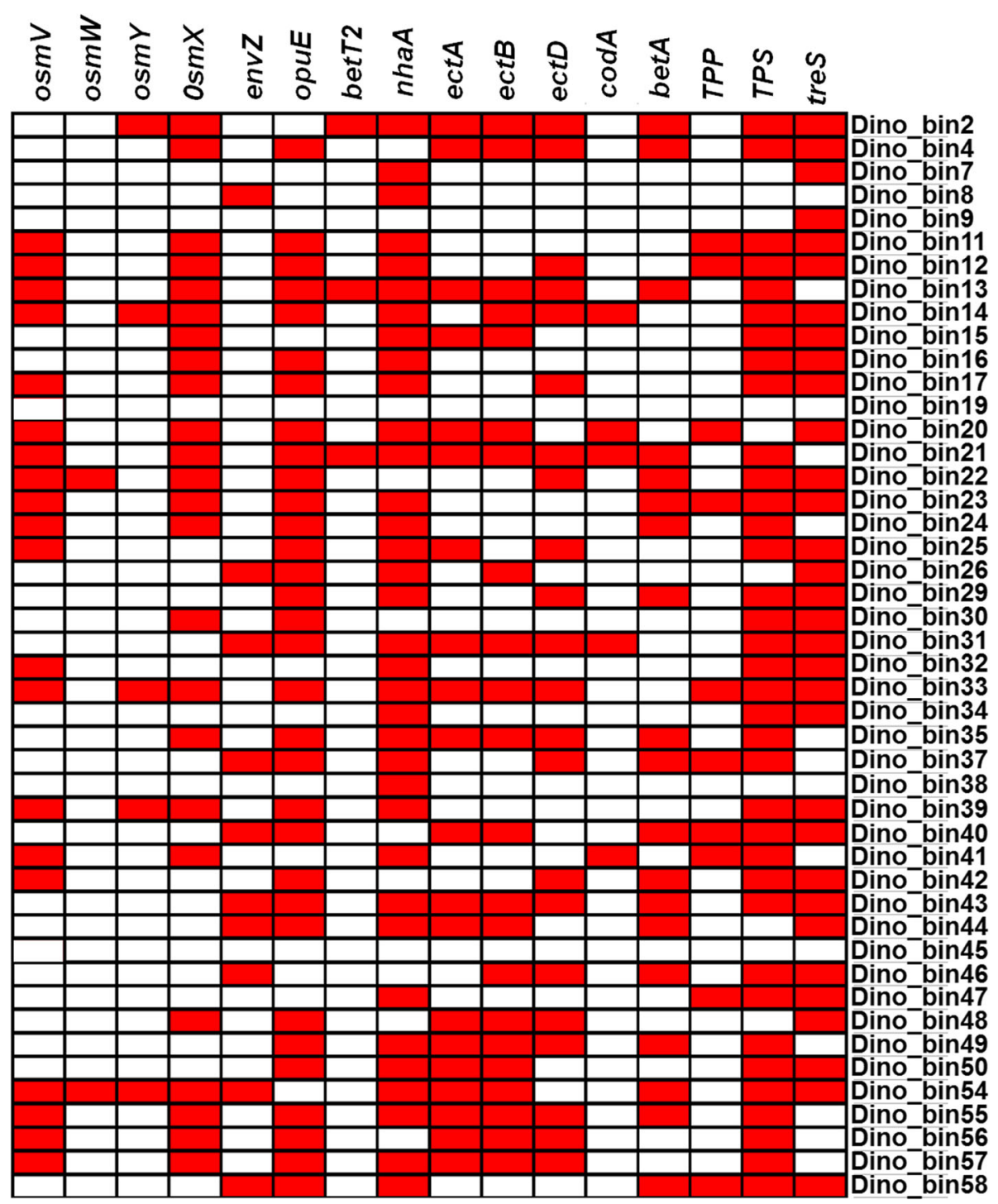

Fig. 4 Presence of functional genes (red) in MAGs involved in coping with high osmolality in the dinosaur fossil bone. Gene abbreviations: osmolarity sensor protein (envZ), osmotically-inducible protein (osmY), osmoprotectant import ATP-binding proteins (osmW and osmV), osmoprotectantbinding protein (osmX), and osmoregulated proline transporter (opuE), osmo-dependent choline transporter (betT2), $\mathrm{Na}(+) / \mathrm{H}(+)$ antiporter (nhaA), L-2,4diaminobutyric acid acetyltransferase (ectA), ectoine synthase (ectC), ectoine hydroxylase (ectD), glycine-betaine producing choline oxidase (codA), oxygendependent choline dehydrogenase (betA), trehalose-6-phosphate phosphatase (TPP), trehalose-6-phosphate synthase (TPS) and trehalose synthase (treS)

sensor protein $(e n v Z)$, osmotically-inducible protein $(\operatorname{osm} Y)$, osmoprotectant import ATP-binding proteins (osmW and osmV), osmoprotectant-binding protein $(o s m X)$, and osmoregulated proline transporter (opuE) were identified in 42 of the 46 MAGs (Fig. 4). The compatible solutes such as glycine-betaine and ectoine are well-known osmoprotectants widely employed by diverse microorganisms [79]. Thirty-three of the 46 MAGs encode the capacity for synthesis of glycine-betaine $(\operatorname{cod} A$ and betA) and ectoine/hydroxyectoine (ect $A$, ectC and ectD) (Fig. 4). Furthermore, two biosynthetic pathways (trehalose-6-phosphate synthase, TPS; and trehalose synthase, treS) for production of trehalose, which could also be important in adapting to high osmolality [80], were identified in 42 of the 46 MAGs (Fig. 4). The prevalence of halotolerant microorganisms and their potential capacity for coping with osmotic stress suggests either a previous exposure to saline formation water [37] or ongoing high salinity $\mathrm{SO}_{4}{ }^{2-}$ fluctuations due to wet/dry cycles in the vadose zone.

\section{Carbon metabolism}

Among all 46 MAGs, only 5 MAGs were predicted to harbor the key genes for $\mathrm{CO}_{2}$ fixation (Figs. 5 and 6). The two MAGs (Dino_bin19 and Dino_bin45) affiliated with Thaumarchaeota (Fig. 1) have the potential for 


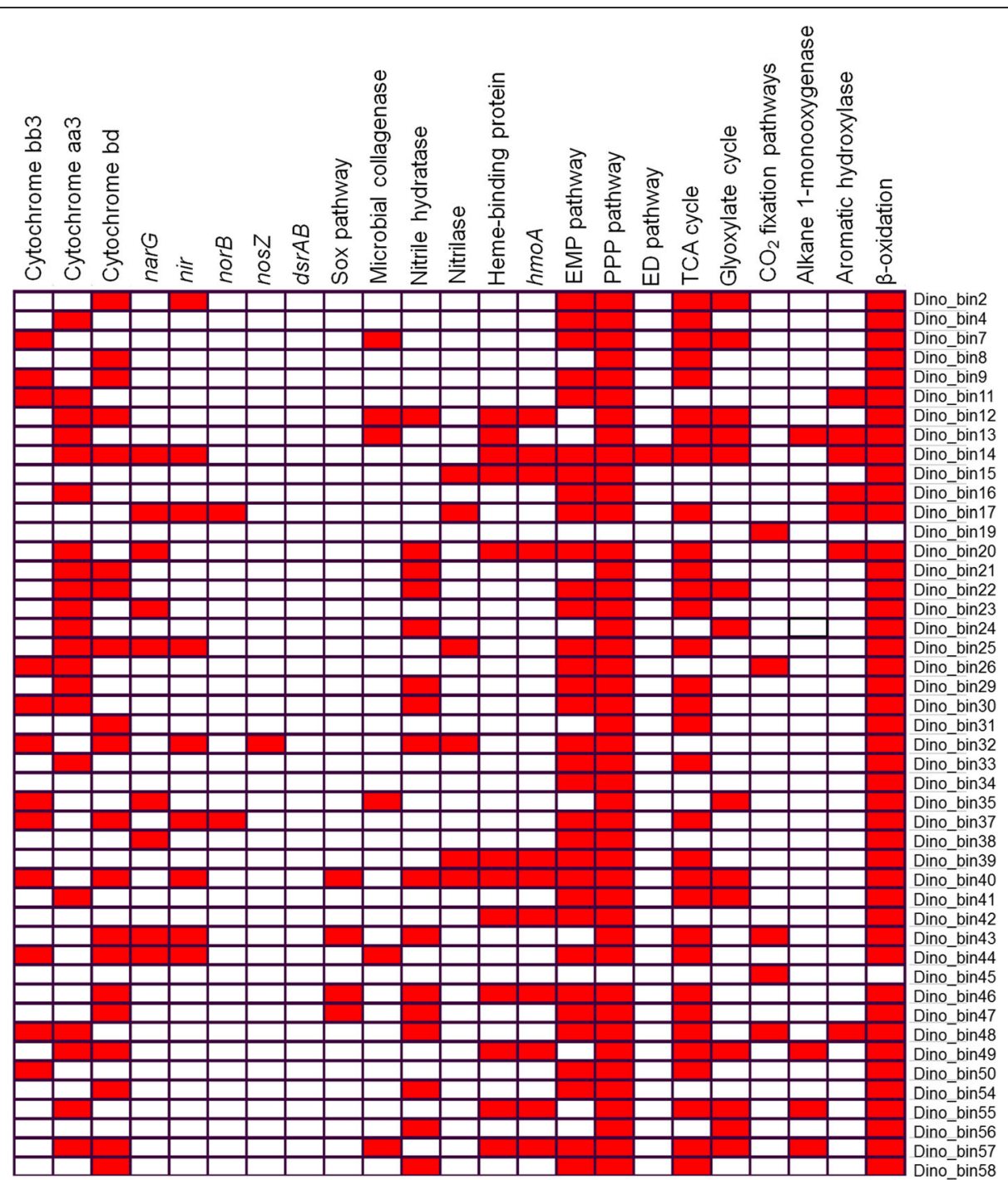

Fig. 5 Presence of key functional genes (red) in MAGs involved in various biogeochemical cycling processes. Abbreviations: membrane bound nitrate reductase (narG), nitrite reductase (nir), nitric oxide reductase (norB) and nitrous oxide reductase (nosZ), dissimilatory sulfite reductase subunit $A$ and $B(D s r A B)$, sulfur oxidation pathway (Sox), heme-degrading monooxygenase (hmoA), Embden-Meyerhof pathway (EMP), pentose phosphate pathway (PPP), Entner-Doudoroff pathway (ED), tricarboxylic acid (TCA) cycle. Note: The $\mathrm{CO}_{2}$ fixation pathways refer to the presence of genes involved either in 3-hydroxyproprionate/4-hydroxybutyrate or reductive TCA pathway. The other pathways such as EMP and TCA indicated that majority of the associated genes (> 70\%) were identified in the genome

$\mathrm{CO}_{2}$ fixation using the archaeal 3-hydroxyproprionate/4hydroxybutyrate pathway that has been well described in ammonia-oxidizing Thaumarchaeota [81]. The Nitrospira-related MAG (Dino_bin_26) and two other MAGs (Dino_bin43 and Dino_bin48) encode genes for ATPcitrate lyase, 2-oxoglutarate:ferredoxin oxidoreductase and pyruvate:ferredoxin oxidoreductase that are involved in the reductive citric acid cycle for $\mathrm{CO}_{2}$ fixation that is found in many bacteria including Nitrospira-related nitrite-oxidizers [82]. The majority of the MAGs are predicted to be heterotrophs using $\mathrm{O}_{2}$ and/or nitrate as terminal electron acceptors (Fig. 5). Numerous genes involved in the metabolism of carbohydrates from complex polysaccharides to simple sugars were identified in most of the MAGs. For instance, many MAGs contain alpha-amylase and oligo-1,6-glucosidase that are involved in the degradation of starch and the subsequent hydrolysis of oligosaccharides. Furthermore, the genes encoding xylosidase and galactosidase were also commonly found among the MAGs. Monomeric carbon substrates such as glucose can be oxidized by the Embden-Meyerhof pathway (33 MAGs), the pentose phosphate pathway (found in 45 MAGs) and EntnerDoudoroff pathway (only Dino_bin14) (Fig. 5). The complete pathway for the tricarboxylic acid cycle was identified in 32 MAGs. By contrast, only 14 MAGs 


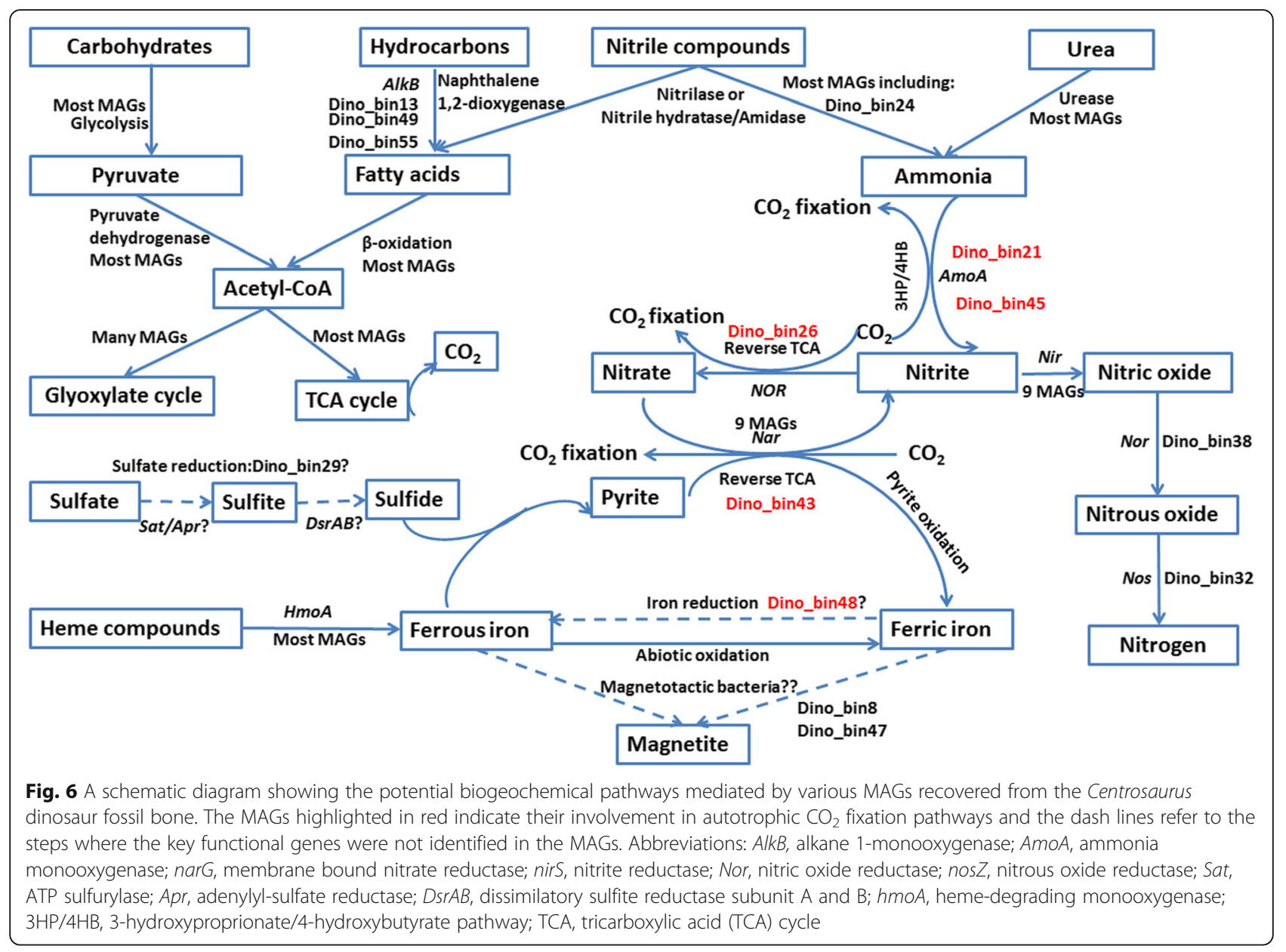

encoded the key enzymes (isocitrate lyase and malate synthase) for the glyoxylate pathway to assimilate C2 compounds like acetyl-CoA (Figs. 5 and 6) in the absence of complex substrates.

Since purported endogenous organics such as collagens and osteocytes have been discovered in various Mesozoic dinosaurs [4-10], we screened all MAGs for their potential to degrade collagens. Microbial collagenases were detected in 5 MAGs (Dino_bin7, Dino bin12, Dino_13, Dino_bin35, and Dino_bin44) affiliated with Actinobacteria and Acidobacteria (Fig. 5), which is consistent with the ubiquity of collagen-degrading microorganisms in various soil environments [83]. Therefore, any preserved collagen peptides, if not shielded from bacterial access, could potentially be degraded by the resident microorganisms in the Centrosaurus bone. Previous analyses by pyrolysis-gas chromatography/mass spectrometry (Py-GC/MS) provided evidence that aromatic hydrocarbons (alkylbenzenes and naphthalenes pyrolysis products) and kerogen (n-alkane/n-alkene doublets in the pyrograms) were present in the Centrosaurus bone and adjacent mudstone [28]. Six MAGs (Dino_ bin11, Dino_bin13, Dino_bin14, Dino_bin16, Dino_ bin17, and Dino_bin20) encode genes for biphenyl 2,3dioxygenase and naphthalene 1,2-dioxygenase to aerobically degrade aromatic hydrocarbons (Fig. 5). The alkane 1-monooxygenase gene $(a l k B)$ involved in the oxidation of alkanes was also found in four MAGs (Dino_bin13, Dino_bin49, Dino_bin55, and Dino_bin57) that are closely affiliated to the genus Amycolatopsis (Table S3 and Fig. 5), which has been implicated in the metabolism of alkanes [84]. Aside from hydrocarbon degradation, most of MAGs have the ability to further oxidize the intermediates of fatty acids via $\beta$-oxidation (Figs. 5 and 6). The $\beta$-oxidation pathway was supported by the presence of all essential genes of acyl-CoA dehydrogenase, enoyl-CoA hydratase, 3-hydroxyacyl-CoA dehydrogenase and acetyl-CoA acetyltransferase.

\section{Nitrogen cycling}

The presence of nitrate and nitrite in the bone (Additional file 2: Table S1) suggests that nitrogen cycling might be an important biogeochemical process inside the bone microenvironments. Twenty MAGs including the dominant Nitriliruptoria-related MAG (Dino_bin24) encode enzymes for catalyzing hydrolysis of aliphatic and aromatic 
nitrile compounds (Fig. 5). Nitrile compounds are produced from biodegradation of amino acids under low $\mathrm{O}_{2}$ conditions [85]. A recent study has also shown that proteinaceous soft tissues can be transformed into Nheterocyclic polymers via oxidative crosslinking with lipids and polysaccharides during fossilization and diagenesis in oxic environments [86]. However, it remains unknown whether such $\mathrm{N}$-rich heterocycles could be further converted to nitrile compounds during later diagenetic processes. Several MAGs associated with Actinobacteria were predicted to use a single-step hydrolysis, which catalyzes the hydrolysis of nitriles to yield carboxylic acids and ammonia using nitrilases (Figs. 5 and 6) [77]. Many other MAGs were predicted to hydrolyze nitriles to the same final products via a two-step hydrolysis involving nitrile hydratase and amidases (Fig. 5). Nitrile hydratase and amidases have been frequently found in diverse microorganisms from soil [87]. Notably, the iron-containing metalloenzyme nitrile hydratase from soil bacteria Rhodococcus $s p$. was also identified in a protein extract from a Tyrannosaurus rex bone in a previous study [11]. It remains unclear whether the expression of nitrile hydratase in dinosaur fossil bones was due to the microbial degradation of nitrile compounds that originated from the bone or the encompassing sediment/soil environment.

The ammonia produced from nitrile degradation could be used as nitrogen sources for the resident microbial community. The hydrolysis of urea catalyzed by ureases found in most of the MAGs could represent another source of ammonia. Two archaeal MAGs (Dino_bin19 and Dino_bin45) affiliated with Thaumarchaeota encode the metabolic capacity for ammonia oxidation by using ammonia monooxygenase (amoA). The nitrite could be further oxidized to nitrate by the Nitrospira-related MAG (Dino_bin26). Although no nitrite oxidoreductase was detected, the MAG (Dino_bin26) was phylogenetically close to other nitrite-oxidizing bacteria based on phylogenetic trees reconstructed from 16S rRNA gene (98\% identity, $1538 \mathrm{bp}$ ) and concatenated ribosomal proteins (Figs. 1 and 3). The MAGs of 6 Actinobacteria, 1 Betaproteobacteria, 1 Chloroflexi, and 1 Acidobacteria contain narG (membrane bound nitrate reductase) gene for dissimilatory nitrate reduction (Fig. 5). The critical gene for nitrite reductase (nirS) was found in 5 Actinobacteria, 1 Acidobacteria, and 3 Proteobacteria MAGs (Fig. 5). The genes encoding nitric oxide reductase (nor $B$ ) and nitrous oxide reductase (nosZ), were present in 3 MAGs (Dino_bin17, Dino_bin32, Dino_bin37). Although none of the MAGs contained the complete set of genes for denitrification, the presence of multiple genes suggested that the microbial populations in the bone have the genetic machinery to potentially reduce nitrate fully to $\mathrm{N}_{2}$ via species interaction when $\mathrm{O}_{2}$ becomes depleted inside the microenvironments.

\section{Potential sulfur and iron metabolism}

Although sulfate was the most abundant electron acceptor for microbial respiration in the bone and mudstone (Additional file 2: Table S1), none of the MAGs encode the $d s r A B$ gene (dissimilatory sulfite reductase) responsible for reducing sulfite to sulfide. Since $\mathrm{O}_{2}$ and nitrate are preferable electron acceptors over sulfate from a thermodynamic point of view, sulfide production linked to sulfate reduction appears to be less important in the Centrosaurus bone in this particular setting at the time of sampling. However, the common presence of framboidal pyrite in fossil bone has been interpreted as evidence that sulfate-reducing bacteria are present during fossilization in anoxic burial environments [88]. Despite the lack of $d s r A B$, the dominant Deltaproteobacteria MAG (Dino_bin29) in the bone was most closely related to a well-known sulfate-reducer Desulfomonile tiedjei [89] (Figs. 1 and 3). Therefore, the activity of this putative sulfate-reducing bacterium may have played a role in at least the recent taphonomy of the Centrosaurus bone. The MAGs from Alphaproteobacteria (Dino bin40, Dino_bin46 and Dino_bin47) and Betaproteobacteria (Dino_bin43) contained the sox gene cluster that is involved in the sulfur oxidation pathway (Fig. 5). The Betaproteobacteria MAG (Dino_bin43) was particularly interesting because one of its closest relatives (Thiobacillus denitrificans) has been documented to couple anaerobic pyrite oxidation to nitrate reduction [90]. Therefore, the dominant Betaproteobacteria in the bone might cause taphonomic alternations to the fossil bone by oxidizing diagenetic pyrite in the fossil during its late diagenetic history. Furthermore, the oxidation of pyrite to sulfate coupled to nitrate reduction [90] might have contributed to the elevated sulfate concentrations in the Centrosaurus bone.

Iron has been previously hypothesized to play an important role in exceptional preservation of soft tissues in Mesozoic fossil bone from deep time [91], although this preservation mechanism has not been conclusively demonstrated. Iron-containing dinosaur biomolecules such as hemoglobin and myoglobin could be important original sources of iron [6], and heme-containing compounds purportedly from the breakdown of hemoglobin have been reported in trabecular bone of Tyrannosaurus rex [92]. Interestingly, 11 MAGs encode genes for hemeuptake proteins and heme-degrading monooxygenase. Therefore, any endogenous heme-containing compounds from the Centrosaurus could have been potentially degraded by the resident microbes to liberate iron into the microenvironments. Many types of iron minerals including iron oxides, iron-bearing carbonates and pyrite form in fossil bones during diagenesis depending upon $\mathrm{pH}$ and redox conditions $[17,93]$. As discussed earlier, pyrite can be oxidized to ferric iron by the Thiobacillus 
denitrificans-like microorganism (Dino_bin43) when coupled to nitrate reduction [90]. On the other hand, $\mathrm{Fe}(\mathrm{III})$ oxides can be used as the terminal electron acceptors by iron-reducing bacteria and multiheme cytochromes have been implicated in ferric iron reduction [94]. Although the Acidimicrobiia-related MAG (Dino_ bin48) was closely related to an iron-reducer Aciditerrimonas ferrireducens [95] (Fig. 1), cytochromes containing multiple heme-binding motifs were not found in the genome. Therefore, more information would be needed to show whether $\mathrm{Fe}(\mathrm{III})$ oxides in the dinosaur bone could possibly be reduced when anoxic conditions prevail in the microenvironments. More intriguingly, two Alphaproteobacteria MAGs (Dino_bin8 and Dino_ bin47) were phylogenetically close to magnetotactic bacteria such as Magnetospirillum marisnigri [96] and Magnetospirillum gryphiswaldense [97] (Fig. 1). These magnetotactic bacteria can accumulate iron to form magnetosomes used to sense the ambient geomagnetic field direction.. However, the genes encoding magnetosomerelated proteins were not identified in these two MAGs (Dino_bin8 and Dino_bin47). Therefore, the role of magnetotactic bacteria in iron uptake and magnetite biomineralization in dinosaur fossil bones warrants further investigation.

\section{Metaproteomics and in situ replication rates}

Mass spectrometry has been employed to identify collagen peptides from Mesozoic dinosaur fossils [5, 8], although their origin is controversial [13, 14]. Metaproteomes were generated from proteins extracted from the Centrosaurus bone and adjacent mudstone using four different methods (see Methods). To search for the existence of endogenous collagen peptides, the obtained metaproteomic datasets were searched against a customized database composed of the Uniprot Vertebrates database and collagen peptides reported from Tyrannosaurus rex [11] and Brachylophosaurus canadensis [8]. No collagen-related peptides were identified in either the Centrosaurus bone or the adjacent mudstone. The failure to detect endogenous collagen peptides from the fossil bone was consistent with our previous results using other analytical methods such as amino acid racemization analysis and Py-GC/MS [28]. Further metaproteomic analyses using a database constructed from the proteomes of all the MAGs indicate that the identified peptide sequences represented proteins expressed from most of the microorganisms inhabiting the bone and mudstone. Due to the much higher microbial biomass inside the bone relative to that of the mudstone [28], more proteins were extracted and identified from the bone (401) than the mudstone (187) (Additional file 7: Table S6 and Additional file 8: Table S7). Although the number of identified proteins varied among all MAGs (Additional file 7: Table S6 and Additional file 8: Table S7), the number of identified proteins was highest among the MAGs (Dino_bin24, Dino_bin20, Dino_bin22 and Dino_bin31 in Additional file 1: Fig. S9) that are abundant in the fossil bone (Fig. 2). Therefore, if any endogenous dinosaur peptides were present, such overwhelming signals from bacteria could complicate their identification and interpretation.

Due to the poor efficiency of protein recovery from the Centrosaurus bone, the number of identified proteins from each MAG was very limited (Additional file 1: Fig. S9). Enzymes involved in $\beta$-oxidation such as acyl-CoA dehydrogenase and enoyl-CoA hydratase were synthesized from several MAGs including the dominant Deltaproteobacteria MAG (Dino_bin29) in the Centrosaurus bone (Fig. 3). NADH-quinone oxidoreductases involved in the aerobic respiratory chains were expressed from several MAGs and thus confirmed the aerobic heterotrophic metabolism among the microbial populations in the Centrosaurus bone. Aromatic hydroxylases involved in the metabolism of naphthalene (1-hydroxy-2-naphthoate) and benzoate (benzoate-CoA ligase) were also identified in some of the MAGs. The metaproteomic data also confirmed that nitrile hydratase was synthesized in situ in one of the Alphaproteobacteria MAGs (Dino_bin58). As mentioned earlier, nitrile hydratase associated with Actinobacteria (Rhodococcus sp.) was identified from the fossil bone of Tyrannosaurus rex [11]. In addition, the gene (betB) involved in biosynthesis of the osmoprotectant glycine betaine was expressed from an Actinobacteria MAG (Dino bin14) (Additional file 7: Table S6). Furthermore, the in situ synthesis of cold shock proteins were identified from many MAGs, suggesting the bone-bearing horizon might have been subject to rapid-onset low temperature due to the wide diurnal temperature range in this area or fastmoving cold fronts. Most of the other identified proteins were either key enzymes involved in biosynthetic pathways (fatty acids and amino acids) or hypothetical proteins with unknown function (Additional file 7: Table S6 and Additional file 7: Table S7).

Since the metaproteomics revealed microbial activity in the Centrosaurus bone and adjacent mudstone, the in situ replication rates of the microbial populations were estimated from metagenomic data using a recently proposed Growth Rate Index (GRiD) [62]. The GRiD values among MAGs were estimated to be in the range of 1.03 and 1.37 and a high correlation $\left(\mathrm{r}^{2}=0.81\right)$ was found between the GRiD values of MAGs within the Centrosaurus bone and those of the same MAGs in the adjacent mudstone (Additional file 1: Fig. S10). These GRiD values are similar to the 1 to 1.5 values reported for bacteria from a shallow groundwater site in Colorado [62]. Therefore, the low GRiD values of MAGs within the Centrosaurus bone and mudstone seem consistent with a shallow subsurface environment likely due to 
limited nutrients fluxes in the Centrosaurus bone and surrounding mudstone. Furthermore, no good correlation was observed between GRiD values and relative abundance of MAGs (Fig. 2 and Additional file 1: Fig. S10). For example, the GRiD values from the dominant MAGs affiliated with Euzebya (Dino_bin24), Deltaproteobacteria (Dino_bin29), Betaproteobacteria (Dino_ bin43) in the Centrosaurus bone were much lower than the less abundant populations from Actinobacteria MAGs (Dino_bin17 and Dino_bin48) (Additional file 5: Table S4 and Fig. S10). Since the GRiD values only provide a snapshot of the in situ growth rate at time of collection, the greater biomass abundance of MAGs in the bone relative to those in the mudstone might be attributed to faster growth rates incurred during favorable conditions in the past. Nevertheless, the metaproteomics and the estimated replication rates further support that the dominantly heterotrophic microbes that have colonized the Centrosaurus bone at some point prior to excavation are metabolically active in the subterranean environment [28].

\section{Implications for the preservation of endogenous organics in Mesozoic dinosaurs}

The Centrosaurus bone microbial community does contain the functional potential to degrade collagen, hemecompounds, N-heterocyclic polymers, and kerogen (Fig. 6), which have been previously reported in fossil bones [4, 40, 86, 92]. All peptide sequences recovered from the Centrosaurus bone were microbial and none matched purported dinosaur or other vertebrae collagen. This contrasts with the metaproteome reported for a $T$. rex that recovered only a few microbial peptides [11]. Despite the high microbial biomass in the Centrosaurus bone, $\sim 5 \times 10^{8}$ cells/g [28], the protein recovery utilizing four different extraction techniques was low. If the characteristics we reported here (i.e. high microbial abundance combined with the enzymatic repertoire to degrade endogenous compounds) are symptomatic of fossil bones near the surface, then it appears that the only way collagens in dinosaur bone could survive is if they were protected from microbial degradation during their entire taphonomic history. A negative fluorescent staining result from an immunoassay targeting peptidoglycan, a common bacterial cell wall constituent, might indicate the microbial abundance in the soft tissue fraction of a B. canadensis and T. rex bone was much less than that of ancient organics of endogenous origins [98]. Even if portions of dinosaur bones remained sealed to micribial colonization, a mechanism is still required to substantively reduce the in situ rate of protein hydrolysis. Because nucleic acids and proteins can be extracted from soft tissue simultaneously and because sequencing is rather affordable, the combined approaches presented here could offer important clues to the remaining questions surrounding the exceptional preservation of dinosaur soft tissues in future studies.

\section{Conclusion}

Combined geochemical, metagenomic and metaproteomic analyses of an excavated Centrosaurus bone and encompassing mudstone revealed a $\mathrm{cm}$-scale bone microenvironment with greater microbial abundance than that of the mudstone, which is likely due to the higher phosphate content of the bone. The Centrosaurus bone microbial community is distinct from that of the encompassing mudstone, which may relate to the higher concentrations of nitrate and sulfate. By using genomeresolved metagenomics, we reconstructed 46 draft genomes (MAGs) that included bacterial members of Nitriliruptoria, Deltaproteobacteria, Betaproteobacteria and Acidimicrobiia who were more abundant in the Centrosaurus bone than in the adjacent mudstone. The majority of the recovered MAGs represented novel taxonomic lineages, previously characterized only by $16 \mathrm{~S}$ rRNA gene sequences. Metagenomic and metaproteomic analyses indicate that the bone microbiome is primarily comprised of active, though slowly growing, aerobic heterotrophs capable of oxidizing a wide range of organic substrates and nitrogenous compounds consistent with the vadose zone environment of the bone. The Centrosaurus bone does contain a mixture of organic compounds [28], some of which are radiocarbon-dead hydrocarbons that could have migrated from underlying gas reservoirs [35] (although a contribution from endogenous, organic geopolymers is possible) and some of which are radiocarbon-active, potentially humic and fulvic acids from recharging meteoric water [99]. The metagenomic data also indicated that the bone and mudstone communities are capable of nitrate reduction under sub-oxic conditions that might prevail under water saturation. Collectively, our genomic-centric analyses revealed that the novel lineages residing in the bone might be involved in the interconnected biogeochemical processes linked to metabolism of carbon, sulfur, nitrogen and iron (Fig. 6). Therefore, the metabolic activity of bone microbiome can cause taphonomic alterations to the fossil bone throughout geological time. In this regard, the prevalence of microbial life in Mesozoic fossils should be considered when searching for endogenous fossil organics preserved through deep time. The fact that these microbes can metabolize diagenetically unstable organics such as collagen protein, as well as thermally stable organics such as kerogen and humiclike nitrogenous polymers, is of concern in the attempt to assume high proportions of protein- or labile lipidderived organics in open systems such as fossil bones are endogenous. Examinations should be done on 
dinosaur bones with different depositional setting, stratigraphy, palaeoclimate and paleogeography to determine whether a relationship exists between fossil bone preservation and the microbial inhabitants, and if living microbial community composition and metabolism are better explained by modern climate and environmental conditions.

\section{Supplementary information}

Supplementary information accompanies this paper at https://doi.org/10. 1186/s40793-020-00355-w.

Additional file 1: Figure S1. Canonical correspondence analysis (CCA) for microbial community and geochemical variables in the Centrosaurus bone (1B5g1 and 1B5g2), EDTA-treated bone (1BEDTA and 1BEDTA2), bone scrapings (1S1 and 1S2) and adjacent mudstone (1M1 and 1M2). Arrows indicate the direction and magnitude of environmental parameters associated with samples (dots) and major bacterial groups on class level (triangles). Figure S2. Selected dominant groups within microbial community from bone and mudstone as determined by $16 \mathrm{~S}$ rRNA amplicon sequencing (A) and genome-resolved metagenomics (B). The relative abundance in $A$ and $B$ was based on the number of OTUs and coverage of MAGs, respectively. The asterisks indicated the statistical difference $\left({ }^{*}<0.05\right.$ and $\left.{ }^{* *}<0.01\right)$ between the bone $(1 \mathrm{~B} 5 \mathrm{~g})$ and mudstone and mudstone $(1 \mathrm{M} 10 \mathrm{~g})$. Figure S3. Pairwise average amino acid identity (AAI) distances among the Euzebya-related MAGs (Dino_bin24 and Dino_bin30) and their closest genomic relatives. Figure S4. Pairwise average amino acid identity (AAI) distances among the Betaproteobacteria-related MAG (Dino_bin43) and its closest genomic relatives. Figure S5. Pairwise average amino acid identity (AAl) distances among the Deltaproteobacteria-related MAG (Dino_bin29) and its closest genomic relatives. Figure S6. Pairwise average amino acid identity (AAI) distances among the Chloroflexi-related MAGs and their closest genomic relatives. Figure S7. Pairwise average amino acid identity (AAI) distances among the Acidimicrobiia-related MAGs and their closest genomic relatives. Figure S8. Pangenomics analysis of the Euzebya-related MAGs and other publically available genomes of rare Actinobacteria associated with the class Nitriliruptoria. Three gene clusters that are only present in Euzebya-related MAG from the dinosaur bone are highlighted as 1, 2, and 3 in red. The two MAGs (Dino_bin24 and Dino_bin30) in this study were highlighted in blue whereas other genomes related to Nitriliruptoria were shown in purple. The core genes refer to the genes that are shared by all species. Figure S9. Number of expressed proteins identified from each MAG in the dinosaur fossil bone $(1 \mathrm{~B} 5 \mathrm{~g})$ and the adjacent mudstone $(1 \mathrm{M} 10 \mathrm{~g})$. The number was based on the total proteins identified from the 8 metaproteomeic datasets generated from proteins extracted with different approaches. Figure S10. GRiD measurement of bacterial MAGs from the metagenomic datasets from Centrosaurus bone and adjacent mudstone. The data points indicate the GRiD values of MAGs that the $\mathbf{d n a A}$ /ori and ter/dif ratios were above 0.8 according to the output results from the GRiD tool.

Additional file 2: Table 1. Geochemical characteristics in water extract from the bone and mudstone.

Additional file 3: Table S2. Statistical summary for MAGs recovered from microbiome in dinosaur fossil bone.

Additional file 4: Table S3. Taxonomic classification based on the GTDB-Tk tool.

Additional file 5: Table S4. Relative abundance of MAGs in each metagenome

Additional file 6: Table S5 Taxonomic identification of MAGs based on homology of $16 \mathrm{~S}$ rRNA gene.

Additional file 7: Table S6. Identified proteins in dinosaur fossil bone

Additional file 8: Table S7. Identified proteins in the adjacent

mudstone.
Additional file 9. Accession numbers for individual MAGs deposited in NCBI database.

\section{Acknowledgements}

Not applicable.

\section{Authors' contributions}

RL, TCO, MCL and ETS conceived and designed the study. ETS collected the sample and aided in DNA extraction. RL, MCL and ZKG analyzed the metagenomic data and reconstructed the draft genomes. RL carried out the phylogenetic analyses, functional annotations of the draft genomes and all other genome-centric analyses. RL spearheaded the manuscript and all authors were involved in reading and editing to improve the final manuscript.

\section{Funding}

This work was financially supported by the Scott Vertebrate Paleontology

Fund from the Department of Geosciences, Princeton University.

\section{Availability of data and materials}

All metagenomic reads and sample information are available at NCBI under BioProject ID PRJNA494230 with the SRA accession numbers of SRR10173838 and SRR10173105. Accession numbers for individual MAGs are provided in Additional file 9: Table S8. All metaproteomic data and identification results were deposited to the ProteomeXchange Consortium via the PRIDE partner repository with the dataset identifier PXD015750.

Ethics approval and consent to participate

Not applicable.

Consent for publication

Not applicable.

\section{Competing interests}

The authors declare that they have no competing interests.

\section{Author details}

${ }^{1}$ Department of Geosciences, Princeton University, B88, Guyot Hall, Princeton University, Princeton, NJ 08544, USA. ${ }^{2}$ Present address: Institute of Deep-Sea Science and Engineering, Chinese Academy of Sciences, Sanya, China. ${ }^{3}$ Integrative Research Center, Section of Earth Sciences, Field Museum of Natural History, Chicago, USA.

Received: 23 February 2020 Accepted: 27 February 2020

Published online: 19 March 2020

References

1. Allentoft ME, Collins M, Harker D, Haile J, Oskam CL, Hale ML, Campos PF, Samaniego JA, Gilbert MTP, Willerslev E. The half-life of DNA in bone: measuring decay kinetics in 158 dated fossils. Proc R Soc B. 2012;279:4724-33.

2. Briggs DE, Summons RE. Ancient biomolecules: their origins, fossilization, and role in revealing the history of life. BioEssays. 2014;36:482-90.

3. Lindahl T. Instability and decay of the primary structure of DNA. Nature. 1993:362:709-15.

4. Lee $Y-C$, Chiang C-C, Huang P-Y, Chung C-Y, Huang TD, Wang C-C, Chen C-I, Chang R-S, Liao C-H, Reisz RR. Evidence of preserved collagen in an Early Jurassic sauropodomorph dinosaur revealed by synchrotron FTIR microspectroscopy. Nat Commu. 2017:8:14220.

5. Schweitzer MH, Schroeter ER, Cleland TP, Zheng W. Paleoproteomics of Mesozoic dinosaurs and other Mesozoic fossils. Proteomics. 2019;1800251.

6. Schweitzer MH, Suo Z, Avci R, Asara JM, Allen MA, Arce FT, Horner JR. Analyses of soft tissue from Tyrannosaurus rex suggest the presence of protein. Science. 2007;316:277-80.

7. Schweitzer MH, Zheng W, Cleland TP, Bern M. Molecular analyses of dinosaur osteocytes support the presence of endogenous molecules. Bone. 2013;52:414-23

8. Schweitzer MH, Zheng W, Organ CL, Avci R, Suo Z, Freimark LM, Lebleu VS, Duncan MB, Vander Heiden MG, Neveu JM. Biomolecular characterization and protein sequences of the Campanian hadrosaur B. canadensis. Science. 2009;324:626-31. 
9. Bertazzo S, Maidment SC, Kallepitis C, Fearn S, Stevens MM, Xie H-n: Fibres and cellular structures preserved in 75-million-year-old dinosaur specimens. Nat Commu. 2015, 6:7352.

10. Cleland TP, Schroeter ER, Zamdborg L, Zheng W, Lee JE, Tran JC, Bern M, Duncan MB, Lebleu VS, AhIf DR. Mass spectrometry and antibody-based characterization of blood vessels from Brachylophosaurus canadensis. J Proteome Res. 2015;14:5252-62.

11. Asara JM, Schweitzer MH, Freimark LM, Phillips M, Cantley LC. Protein sequences from mastodon and Tyrannosaurus rex revealed by mass spectrometry. Science. 2007;316:280-5.

12. Kaye TG, Gaugler G, Sawlowicz Z. Dinosaurian soft tissues interpreted as bacterial biofilms. PLoS One. 2008;3:e2808.

13. Buckley M, Walker A, Ho S, Yang Y, Smith C, Ashton P, Oates J, Cappellini E, Koon H, Penkman K: Comment on "Protein sequences from mastodon and Tyrannosaurus rex. Science 2008, 319: 33c.

14. Buckley M, Warwood S, van Dongen B, Kitchener AC, Manning PL. A fossil protein chimera; difficulties in discriminating dinosaur peptide sequences from modern cross-contamination. Proc R Soc B. 2017;284: 20170544

15. Saitta ET, Fletcher I, Martin P, Pittman M, Kaye TG, True LD, Norell MA, Abbott GD, Summons RE, Penkman K. Preservation of feather fibers from the Late Cretaceous dinosaur shuvuuia deserti raises concern about immunohistochemical analyses on fossils. Org Geoche. 2018;125:142-51.

16. Iniesto M, Buscalioni ÁD, Guerrero MC, Benzerara K, Moreira D, LópezArchilla Al. Involvement of microbial mats in early fossilization by decay delay and formation of impressions and replicas of vertebrates and invertebrates. Sci Rep. 2016;6:25716.

17. Kremer B, Owocki K, Królikowska A, Wrzosek B, Kazmierczak J. Mineral microbial structures in a bone of the Late Cretaceous dinosaur Saurolophus angustirostris from the Gobi Desert, Mongolia-a Raman spectroscopy study. Palaeogeogr Palaeoclimatol Palaeoecol. 2012;358:51-61.

18. Raff RA, Andrews ME, Pearson RL, Turner FR, Saur ST, Thomas DC, Eagan JL, Raff EC. Microbial ecology and biofilms in the taphonomy of soft tissues. Palaios. 2014;29:560-9.

19. Briggs DE: The role of biofilms in the fossilization of non-biomineralized tissues. In Fossil and recent biofilms. Springer; 2003: 281-290.

20. Child A. Towards and understanding of the microbial decomposition of archaeological bone in the burial environment. Archaeol. Sci. 1995;22:165-74.

21. Peterson JE, Lenczewski ME, Clawson SR, Warnock JP. Role of sediment size and biostratinomy on the development of biofilms in recent avian vertebrate remains. Front Earth Sci. 2017;5:30.

22. Pinheiro FL, Horn BL, Schultz CL, de Andrade JA, Sucerquia PA. Fossilized bacteria in a Cretaceous pterosaur headcrest. Lethaia. 2012;45:495-9.

23. Peterson JE, Lenczewski ME, Scherer RP. Influence of microbial biofilms on the preservation of primary soft tissue in fossil and extant archosaurs. Plos one. 2010;5:e13334.

24. Pfretzschner H-U. Collagen gelatinization: the key to understand early bonediagenesis. Palaeontogr Abt B. 2006:135-48.

25. Brown CM, Henderson DM, Vinther J, Fletcher I, Sistiaga A, Herrera J, Summons RE: An exceptionally preserved three-dimensional armored dinosaur reveals insights into coloration and Cretaceous predator-prey dynamics. Curr Biol. 2017, 27:2514-2521. e2513.

26. Melendez I, Grice K, Schwark L. Exceptional preservation of Palaeozoic steroids in a diagenetic continuum. Sci rep. 2013;3:2768.

27. Clements T, Dolocan A, Martin P, Purnell MA, Vinther J, Gabbott SE. The eyes of Tullimonstrum reveal a vertebrate affinity. Nature. 2016;532:500.

28. Saitta ET, Liang R, Lau MC, Brown CM, Longrich NR, Kaye TG, Novak BJ, Salzberg SL, Norell MA, Abbott GD. Cretaceous dinosaur bone contains recent organic material and provides an environment conducive to microbial communities. eLife. 2019;8:e46205.

29. Haouchar D, Haile J, McDowell MC, Murray DC, White NE, Allcock RJ, Phillips MJ, Prideaux GJ, Bunce M. Thorough assessment of DNA preservation from fossil bone and sediments excavated from a late Pleistocene-Holocene cave deposit on Kangaroo Island South Australia. Quat Sci Rev. 2014;84:56-64.

30. Der Sarkissian C, Ermini L, Jónsson H, Alekseev A, Crubezy E, Shapiro B, Orlando L: Shotgun microbial profiling of fossil remains. Mol Ecol. 2014, 23: 1780-1798.

31. Danise S, Cavalazzi B, Dominici S, Westall F, Monechi S, Guioli S. Evidence of microbial activity from a shallow water whale fall (Voghera, northern Italy). Palaeogeogr Palaeoclimatol Palaeoecol. 2012;317:13-26.
32. Grealy A, Macken A, Allentoft ME, Rawlence NJ, Reed E, Bunce M. An assessment of ancient DNA preservation in Holocene-Pleistocene fossil bone excavated from the world heritage Naracoorte Caves South Australia. J Quat Sci. 2016;31:33-45.

33. Uritskiy GV, DiRuggiero J, Taylor J. MetaWRAP_a flexible pipeline for genome-resolved metagenomic data analysis. Microbiome. 2018;6:158.

34. Eberth DA. Origins of dinosaur bonebeds in the Cretaceous of Alberta Canada. Can. J Earth Sci. 2015;52:655-81.

35. Taylor S, Sherwood Lollar B, Wassenaar I. Bacteriogenic ethane in nearsurface aquifers: Implications for leaking hydrocarbon well bores. Environ Sci Technol. 2000;34:4727-32.

36. Ayalon A, Longstaffe FJ. Oxygen isotope studies of diagenesis and porewater evolution in the Western Canada sedimentary basin; evidence from the Upper Cretaceous basal Belly River Sandstone. Alberta J Sediment Res. 1988:58:489-505.

37. Bachu S, Michael K. Possible controls of hydrogeological and stress regimes on the producibility of coalbed methane in Upper Cretaceous-Tertiary strata of the Alberta basin, Canada. AAPG bulletin. 2003:87:1729-54.

38. Hendry MJ, Schwartz FW. The chemical evolution of ground water in the Milk River aquifer, Canada. Groundwater. 1990;28:253-61.

39. Fabryka-Martin J, Whittemore DO, Davis S, Kubik P, Sharma P. Geochemistry of halogens in the Milk River aquifer, Alberta Canada. J Appl Geochem. 1991;6:447-64.

40. Schroeter ER, DeHart CJ, Cleland TP, Zheng W, Thomas PM, Kelleher NL, Bern M, Schweitzer MH. Expansion for the Brachylophosaurus canadensis collagen I sequence and additional evidence of the preservation of Cretaceous protein. J Proteome Res. 2017;16:920-32.

41. Liang R, Lau M, Vishnivetskaya T, Lloyd KG, Wang W, Wiggins J, Miller J, Pfiffner S, Rivkina EM, Onstott T: Predominance of anaerobic, spore-forming bacteria in metabolically active microbial communities from ancient Siberian permafrost. Appl Environ Microbiol. 2019:AEM. 00560-00519.

42. Li D, Luo R, Liu C-M, Leung C-M, Ting H-F, Sadakane K, Yamashita H, Lam T-W. MEGAHIT v1. 0: a fast and scalable metagenome assembler driven by advanced methodologies and community practices. Methods. 2016;102:3-11.

43. Kang DD, Froula J, Egan R, Wang Z. MetaBAT, an efficient tool for accurately reconstructing single genomes from complex microbial communities. PeerJ. 2015;3:e1165.

44. Wu Y-W, Simmons BA, Singer SW. MaxBin 2.0: an automated binning algorithm to recover genomes from multiple metagenomic datasets. Bioinformatics. 2015;32:605-7.

45. Alneberg J, Bjarnason BS, De Bruijn I, Schirmer M, Quick J, ljaz UZ, Lahti L, Loman NJ, Andersson AF, Quince C. Binning metagenomic contigs by coverage and composition. Nat Methods. 2014;11:1144.

46. Parks DH, Imelfort M, Skennerton CT, Hugenholtz P, Tyson GW: CheckM: Assessing the quality of microbial genomes recovered from isolates, single cells, and metagenomes. Genome Res.2015, 25:1043-1055.

47. Bankevich A, Nurk S, Antipov D, Gurevich AA, Dvorkin M, Kulikov AS, Lesin VM, Nikolenko SI, Pham S, Prjibelski AD. SPAdes: a new genome assembly algorithm and its applications to single-cell sequencing. J Comput Biol. 2012:19:455-77.

48. Seemann T. Prokka: rapid prokaryotic genome annotation. Bioinformatics. 2014:30:2068-9.

49. Tanizawa Y, Fujisawa T, Nakamura Y. DFAST: a flexible prokaryotic genome annotation pipeline for faster genome publication. Bioinformatics. 2017;34: 1037-9.

50. Aziz RK, Bartels D, Best AA, DeJongh M, Disz T, Edwards RA, Formsma K, Gerdes S, Glass EM, Kubal M. The RAST Server: rapid annotations using subsystems technology. BMC genomics. 2008;9:75.

51. Kanehisa M, Sato Y, Morishima K. BlastKOALA and GhostKOALA: KEGG tools for functional characterization of genome and metagenome sequences. J. Mol Biol. 2016;428:726-31.

52. Eren AM, Esen ÖC, Quince C, Vineis JH, Morrison HG, Sogin ML, Delmont TO. Anvi'o: an advanced analysis and visualization platform for omics data. PeerJ. 2015;3:e1319.

53. Lagesen $\mathrm{K}$, Hallin $\mathrm{P}$, Rødland EA, Stærfeldt $\mathrm{H}-\mathrm{H}$, Rognes $\mathrm{T}$, Ussery DW. RNAmmer: consistent and rapid annotation of ribosomal RNA genes. Nucleic Acids Res. 2007:35:3100-8.

54. Edgar RC. MUSCLE: multiple sequence alignment with high accuracy and high throughput. Nucleic Acids Res. 2004;32:1792-7. 
55. Kumar S, Stecher G, Tamura K. MEGA7: molecular evolutionary genetics analysis version 7.0 for bigger datasets. Mol Biol Evol. 2016;33:1870-4.

56. Hug LA, Baker BJ, Anantharaman K, Brown CT, Probst AJ, Castelle CJ, Butterfield CN, Hernsdorf AW, Amano Y, Ise K. A new view of the tree of life. Nat Microbiol. 2016;1:16048.

57. Capella-Gutiérrez S, Silla-Martínez JM. Gabaldón T: trimAl: a tool for automated alignment trimming in large-scale phylogenetic analyses. Bioinformatics. 2009;25:1972-3.

58. Stamatakis A. RAxML version 8: a tool for phylogenetic analysis and postanalysis of large phylogenies. Bioinformatics. 2014;30:1312-3.

59. Letunic I, Bork P. Interactive tree of life (TOL) V3: an online tool for the display and annotation of phylogenetic and other trees. Nucleic Acids Res. 2016;44:W242-5.

60. Parks DH, Chuvochina M, Waite DW, Rinke C, Skarshewski A, Chaumeil P-A Hugenholtz P. A standardized bacterial taxonomy based on genome phylogeny substantially revises the tree of life. Nat Biotechnol. 2018:36:996-1004.

61. Rodriguez-R LM, Konstantinidis KT. The enveomics collection: a toolbox for specialized analyses of microbial genomes and metagenomes. PeerJ Preprints. 2016

62. Emiola A, Oh J. High throughput in situ metagenomic measurement of bacterial replication at ultra-low sequencing coverage. Nat Commun. 2018;9:4956.

63. PJ MM, Holmes S. Phyloseq: an R package for reproducible interactive analysis and graphics of microbiome census data. PloS one. 2013;8:e61217.

64. Lau MC, Kieft TL, Kuloyo O, Linage-Alvarez B, Van Heerden E, Lindsay MR, Magnabosco C, Wang W, Wiggins JB, Guo L. An oligotrophic deepsubsurface community dependent on syntrophy is dominated by sulfurdriven autotrophic denitrifiers. Proc Natl Acad Sci. 2016:113:E7927-36.

65. Chourey K, Jansson J, VerBerkmoes N, Shah M, Chavarria KL, Tom LM, Brodie EL, Hettich RL. Direct cellular lysis/protein extraction protocol for soil metaproteomics. J Proteome Res. 2010;9:6615-22.

66. Rappsilber J, Mann M, Ishihama Y. Protocol for micro-purification, enrichment, pre-fractionation and storage of peptides for proteomics using StageTips. Nat Protoc. 2007;2:1896-906.

67. Cox J, Mann M. MaxQuant enables high peptide identification rates, individualized ppb-range mass accuracies and proteome-wide protein quantification. Nat Biotechnol. 2008;26:1367.

68. Hyatt D, Chen G-L, LoCascio PF, Land ML, Larimer FW, Hauser L. Prodigal: prokaryotic gene recognition and translation initiation site identification. BMC bioinformatics. 2010;11:119.

69. Bowers RM, Kyrpides NC, Stepanauskas R, Harmon-Smith M, Doud D, Reddy T, Schulz F, Jarett J, Rivers AR, Eloe-Fadrosh EA. Minimum information about a single amplified genome (MISAG) and a metagenome-assembled genome (MIMAG) of bacteria and archaea. Nat Biotechnol. 2017;35:725.

70. Medlar AJ, Törönen P, Holm L. AAl-profiler: fast proteome-wide exploratory analysis reveals taxonomic identity, misclassification and contamination. Nucleic Acids Res. 2018:46:W479-85

71. Kurahashi M, Fukunaga Y, Sakiyama Y, Harayama S, Yokota A. Euzebya tangerina gen. nov., sp. nov., a deeply branching marine actinobacterium isolated from the sea cucumber Holothuria edulis, and proposal of Euzebyaceae fam. nov., Euzebyales ord. nov. and Nitriliruptoridae subclassis nov. Int J Syst Evol Microbiol. 2010;60:2314-9.

72. Xu L, Sun C, Huang M, Wu Y-H, Yuan C-Q, Dai W-H, Ye K, Han B, Xu X-W. Complete genome sequence of Euzebya sp. DY32-46, a marine Actinobacteria isolated from the Pacific Ocean. Mar Genomics. 2019;44:65-9.

73. Yin Q, Zhang L, Song Z-M, Wu Y, Hu Z-L, Zhang X-H, Zhang Y, Yu M, Xu Y. Euzebya rosea sp. nov., a rare actinobacterium isolated from the East China Sea and analysis of two genome sequences in the genus Euzebya. Int J Syst Evol Microbiol. 2018;68:2900-5

74. Mizuno CM, Rodriguez-Valera F, Ghai R. Genomes of planktonic acidimicrobiales: widening horizons for marine actinobacteria by metagenomics. MBio. 2015;6:e02083-14.

75. Martijn J, Vosseberg J, Guy L, Offre P, Ettema TJ. Deep mitochondrial origin outside the sampled alphaproteobacteria. Nature. 2018;557:101.

76. Tully BJ, Sachdeva R, Graham ED, Heidelberg JF. 290 metagenomeassembled genomes from the Mediterranean Sea: a resource for marine microbiology. PeerJ. 2017;5:e3558.

77. Watson SW, Bock E, Valois FW, Waterbury JB, Schlosser U. Nitrospira marina gen. nov. sp. nov.: a chemolithotrophic nitrite-oxidizing bacterium. Arch Microbiol. 1986;144:1-7.

78. Keuter S, Kruse M, Lipski A, Spieck E. Relevance of Nitrospira for nitrite oxidation in a marine recirculation aquaculture system and physiological features of a Nitrospira marina-like isolate. Environ Microbiol. 2011:13:2536-47.
79. Poolman B, Glaasker E. Regulation of compatible solute accumulation in bacteria. Mol Microbiol. 1998;29:397-407.

80. Reina-Bueno M, Argandoña M, Salvador M, Rodríguez-Moya J, IglesiasGuerra F, Csonka LN, Nieto JJ, Vargas C. Role of trehalose in salinity and temperature tolerance in the model halophilic bacterium Chromohalobacter salexigens. PLoS One. 2012;7:e33587.

81. Pester M, Schleper C, Wagner M. The Thaumarchaeota: an emerging view of their phylogeny and ecophysiology. Curr Opin Microbiol. 2011;14:300-6.

82. Lücker S, Wagner M, Maixner F, Pelletier E, Koch H, Vacherie B, Rattei T, Damsté JSS, Spieck E, Le Paslier D. A Nitrospira metagenome illuminates the physiology and evolution of globally important nitrite-oxidizing bacteria. Proc Natl Acad Sci. 2010;107:13479-84.

83. Vraný B, Hnátková Z, Lettl A. Occurrence of collagen-degrading microorganisms in associations of mesophilic heterotrophic bacteria from various soils. Folia Microbiol. 1988;33:458-61.

84. Bourguignon N, Bargiela R, Rojo D, Chernikova TN, de Rodas SAL, GarcíaCantalejo J, Näther DJ, Golyshin PN, Barbas C, Ferrero M. Insights into the degradation capacities of Amycolatopsis tucumanensis DSM 45259 guided by microarray data. World J Microbiol Biotechnol. 2016;32:201.

85. Harper D, Gibbs P. Identification of isobutyronitrile and isobutyraldoxime O-methyl ether as volatile microbial catabolites of valine. Biochem J. 1979;182:609-11.

86. Wiemann J, Fabbri M, Yang T-R, Stein K, Sander PM, Norell MA, Briggs DE. Fossilization transforms vertebrate hard tissue proteins into $\mathrm{N}$-heterocyclic polymers. Nat Commun. 2018:9:4741.

87. Precigou S, Goulas P, Duran R. Rapid and specific identification of nitrile hydratase (NHase)-encoding genes in soil samples by polymerase chain reaction. FEMS Microbiol Lett. 2001;204:155-61.

88. Turner-Walker $\mathrm{G}$, Jans $M$. Reconstructing taphonomic histories using histological analysis. Palaeogeogr Palaeoclimatol Palaeoecol. 2008;266:227-35.

89. DeWeerd KA, Mandelco L, Tanner RS, Woese CR, Suflita JM. Desulfomonile tiedjei gen. nov. and sp. nov., a novel anaerobic, dehalogenating, sulfatereducing bacterium. Arch Microbiol. 1990;154:23-30

90. Bosch J, Lee K-Y, Jordan G, Kim K-W, Meckenstock RU. Anaerobic, nitratedependent oxidation of pyrite nanoparticles by Thiobacillus denitrificans. Environ Sci Technol. 2012:46:2095-101.

91. Schweitzer MH, Zheng W, Cleland TP, Goodwin MB, Boatman E, Theil E, Marcus MA, Fakra SC. A role for iron and oxygen chemistry in preserving soft tissues, cells and molecules from deep time. Proc R Soc B. 2014;281:20132741.

92. Schweitzer MH, Marshall M, Carron K, Bohle DS, Busse SC, Arnold EV, Barnard D, Horner J, Starkey JR. Heme compounds in dinosaur trabecular bone. Proc Natl Acad Sci. 1997;94:6291-6.

93. Bao H, Koch PL, Hepple RP. Hematite and calcite coatings on fossil vertebrates. J Sediment Res. 1998;68:727-38.

94. Londer YY, Pokkuluri PR, Tiede DM, Schiffer M. Production and preliminary characterization of a recombinant triheme cytochrome c7 from Geobacter sulfurreducens in Escherichia coli. Biochim Biophys Acta. 2002;1554:202-11.

95. Itoh T, Yamanoi K, Kudo T, Ohkuma M, Takashina T. Aciditerrimonas ferrireducens gen. nov., sp. nov., an iron-reducing thermoacidophilic actinobacterium isolated from a solfataric field. Int J Syst Evol Microbiol. 2011:61:1281-5.

96. Dziuba M, Koziaeva V, Grouzdev D, Burganskaya E, Baslerov R, Kolganova T, Chernyadyev A, Osipov G, Andrianova E, Gorlenko V. Magnetospirillum caucaseum sp. nov., Magnetospirillum marisnigri sp. nov. and Magnetospirillum moscoviense sp. nov., freshwater magnetotactic bacteria isolated from three distinct geographical locations in European Russia. Int J Syst Evol Microbiol. 2016;66:2069-77.

97. Schleifer KH, Schüler D, Spring S, Weizenegger M, Amann R, Ludwig W, Köhler M. The genus Magnetospirillum gen. nov. Description of Magnetospirillum gryphiswaldense sp. nov. and transfer of Aquaspirillum magnetotacticum to Magnetospirillum magnetotacticum comb. nov. Syst Appl Microbiol. 1991;14:379-85.

98. Schweitzer MH, Moyer AE, Zheng W. Testing the hypothesis of biofilm as a source for soft tissue and cell-like structures preserved in dinosaur bone. PloS one. 2016;11:e0150238.

99. Murphy EM, Davis SN, Long A, Donahue D, Jull AT. Characterization and isotopic composition of organic and inorganic carbon in the Milk River Aquifer. Water Resour Res. 1989;25:1893-905.

\section{Publisher's Note}

Springer Nature remains neutral with regard to jurisdictional claims in published maps and institutional affiliations. 